\title{
Plant terpenes: defense responses, phylogenetic analysis, regulation and clinical applications
}

\author{
Bharat Singh $\cdot$ Ram A. Sharma
}

Received: 12 March 2014/Accepted: 10 April 2014/Published online: 29 April 2014

(C) The Author(s) 2014. This article is published with open access at Springerlink.com

\begin{abstract}
The terpenoids constitute the largest class of natural products and many interesting products are extensively applied in the industrial sector as flavors, fragrances, spices and are also used in perfumery and cosmetics. Many terpenoids have biological activities and also used for medical purposes. In higher plants, the conventional acetate-mevalonic acid pathway operates mainly in the cytosol and mitochondria and synthesizes sterols, sesquiterpenes and ubiquinones mainly. In the plastid, the non-mevalonic acid pathway takes place and synthesizes hemi-, mono-, sesqui-, and diterpenes along with carotenoids and phytol tail of chlorophyll. In this review paper, recent developments in the biosynthesis of terpenoids, indepth description of terpene synthases and their phylogenetic analysis, regulation of terpene biosynthesis as well as updates of terpenes which have entered in the clinical studies are reviewed thoroughly.
\end{abstract}

Keywords Terpenes - Terpene synthase - Phylogenetic analysis · Clinical trials

\section{Introduction}

Plants produce various types of secondary metabolites, many of which have been subsequently exploited by humans for their beneficial roles in a diverse array of

\section{B. Singh $(\bowtie)$}

AIB, Amity University Rajasthan, NH-11C, Kant Kalwar, Jaipur 303 002, India

e-mail: bharatsingh217@gmail.com; bsingh@jpr.amity.edu

R. A. Sharma

Department of Botany, University of Rajasthan,

Jaipur 302 055, India biological functions (Balandrin et al. 1985). Several terpenoids have their roles in plant defense against biotic and abiotic stresses or they are treated as signal molecules to attract the insects of pollination. Out of the investigated terpenoids, many have pharmacological and biological activities and are, therefore, interesting for medicine and biotechnology. The first step of terpenoid biosynthesis is generation of $\mathrm{C}_{5}$ unit like as isopentenyl diphosphate (IPP) or dimethylallyl diphosphate (DMAPP). For this study, two different separate pathways have been investigated that can generate the $\mathrm{C}_{5}$ unit: the mevalonate and methylerythritol phosphate (MEP) pathway. On the basis of $\mathrm{C}_{5}$ units, we can classify the terpenoids as $\mathrm{C}_{5}$ (hemiterpenes), $\mathrm{C}_{10}$ (monoterpenes), $\mathrm{C}_{15}$ (sesquiterpenes), $\mathrm{C}_{20}$ (diterpenes), $\mathrm{C}_{25}$ (sesterpenes), $\mathrm{C}_{30}$ (triterpenes), $\mathrm{C}_{40}$ (tetraterpenes), $>\mathrm{C}_{40}$ (polyterpenes) (Ashour et al. 2010; Martin et al. 2003).

The terpene synthases are responsible for the synthesis of terpenes; they can easily acquire new catalytic properties by minor changes in the structures (Keeling et al. 2008). The synthesis of monoterpenes is initiated by dephosphorylation and ionization of geranyl diphosphate to geranyl carbocation (Huang et al. 2010) and the synthesis of sesquiterpene starts with the ionization of farnesyl diphosphate to farnesyl cation, which can also be isomerized to nerolidyl cation (Degenhardt et al. 2009). Diterpenes are synthesized by diterpene synthases in two different pathways: via the ionization of diphosphate, as catalyzed by class I enzyme and the other is via the substrate protonation at the 14, 15-double bond of geranyl geranyl diphosphate; reaction is catalyzed by class II enzymes (Tholl 2006). The nonsteroidal triterpenoids are produced by conversion of squalene into oxidosqualene and cyclization via formation of dammarenyl cation; reaction is catalyzed by oxidosqualene cyclases (Phillips et al. 2006). Many terpenoids also possess the pharmaceutical properties and currently 
are being used in clinical practices. Among these terpenoids, taxol (diterpene) of Taxus buccata and artemisinin (sesquiterpene lactone) from Artemisia аппиа are well known antineoplastic and antimalarial agents (Croteau et al. 2006; Pollier et al. 2011).

This review deals with biosynthesis of terpenoids, phylogeny of terpene synthases, regulation of terpene biosynthesis, and also about the studies of the clinical trials of terpenoids. This review highlights the current approaches of the phylogenetic analysis of terpene synthases and regulation of terpenoids.

\section{Biosynthesis of terpenoids}

Terpenoids are important for plant survival and also possess biological and pharmacological properties that are beneficial to humans. In plants, isopentenyl diphosphate (IPP) and dimethylallyl diphosphate (DMAPP) can be synthesized via two compartmentalized pathways. The mevalonic acid pathway of terpenoid biosynthesis operates in cytosol, the endoplasmic reticulum and peroxisomes (Carrie et al. 2007; Hemmerlin et al. 2003; Dudareva et al. 2006; Leivar et al. 2005; Merret et al. 2007; Sapir-Mir et al. 2008; Simkin et al. 2011; Lange and Ahkami 2013) (Fig. 1). The condensation of acetyl CoA three units leads to the synthesis of 3-hydroxy3-methylglutaryl $\mathrm{CoA}$, which later on produces mevalonic acid. The mevalonic acid converted to isopentenyl diphosphate through the process of the phosphorylation and decarboxylation. 3-hydroxy-3-methylglutaryl CoA reductase catalyzes the reduction of 3-hydroxy-3-methylglutaryl CoA to mevalonic acid (Luskey and Stevens 1985; Basson et al. 1988; Igual et al. 1992; Rodwell et al. 2000). In Arabidopsis thaliana, mevalonate-5-diphosphate is produced from mevalonic acid by the phosphorylation and the whole reaction is catalyzed by mevalonate kinase and

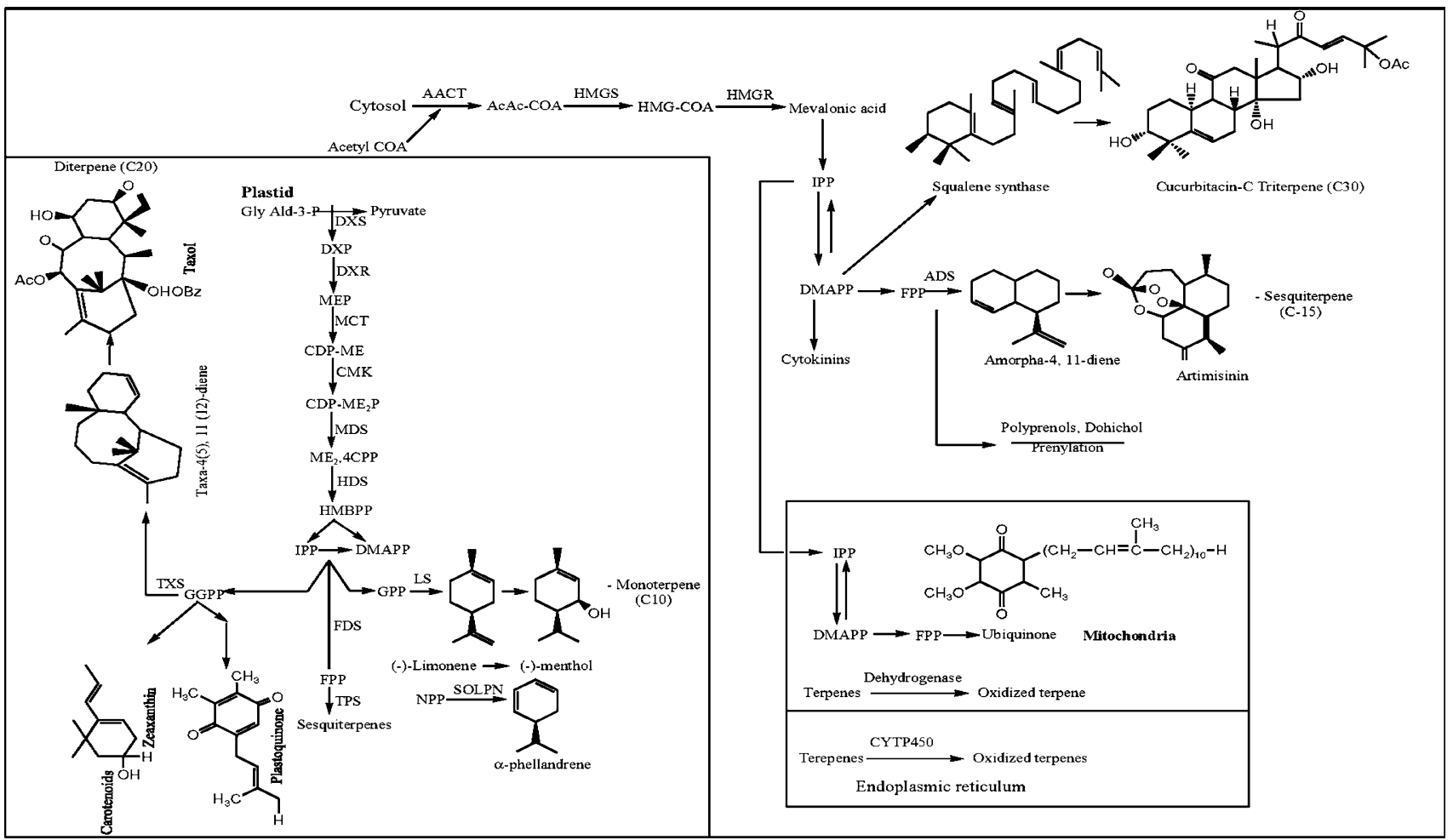

Fig. 1 Schematic overview of monoterpenoid, sesquiterpenoid, diterpenoid and triterpenoid biosynthetic pathways. AACT acetoacetylCoA thiolase, AcAc-CoA acetoacetyl-CoA, HMGS HMG-CoA synthase, HMG-CoA 3-hydroxy-3-methylglutaryl, HMGR HMG-CoAreductase, IPP isopentenyl diphosphate, DMAPP dimethylallyl diphosphate, FPP farnesyl pyrophosphate, $A D S$ amorpha-4,11-diene synthase, CYT450 cytochrome $\mathrm{P}_{450}$ hydroxylase, GlyAld-3P glyceraldehyde-3-phosphate, DXP deoxyxylulose-5-phosphate, DXS DXP synthase, MEP methylerythritol-4-phosphate, DXR DXP reductoisomerase, $C D P$-OME 4-(cytidine-5' -diphospho)-2-C-methyl-D-erythritol, MCT 2-C-methyl-D-erythritol-4-phosphate-cytidylyl transferase,
$C D P-M E 2 P$ 4-(cytidine-5'-diphospho)-2-C-methyl-D-erythritol phosphate, $C M K$ CDP-ME Kinase, $M E 2$, 4cPP 2-C-methyl-D-erythritol, 2,4-cyclodiphosphate, $M D S$ 2-C-methyl-D-erythritol-2,4-cyclodiphosphate synthase, $H M B P P(E)$-4-hydroxy-3-methylbut-2-enyl diphosphate, $H D S(E)$-4-hydroxy-3-methylbut-2-enyl diphosphate synthase, $G P P$ geranyl diphosphate, $L S$ limonene synthase, NPP neryl diphosphate, SOLPN $\alpha$-phellandrene synthase, FDS farnesyl diphosphate synthase. Similarly chemical structures of (-)-methanol, $\alpha$-phellandrene; taxol, artemisinin and cucurbitacin $\mathrm{C}$ are shown as representative examples of terpenoids 
phosphomevalonate kinase (Tsay and Robinson 1991; Lluch et al. 2000). Later on, the mevalonate-5-diphosphate decarboxylase catalyzes the conversion of mevalonate-5-diphosphate to isopentenyl diphosphate, which is the end product of mevalonic acid pathway of terpenoid biosynthesis (DhePaganon et al. 1994) (Fig. 1).

Another part of terpenoid biosynthetic pathway starts in plastid by the condensation of pyruvic acid and glyceraldehydes-3-phosphate, which leads to the synthesis of 1-deoxy-D-xylulose 5-phosphate. The reaction is catalyzed by the enzyme as 1-deoxy-D-xylulose 5-phosphate synthase (Sprenger et al. 1997). The 1-deoxy-D-xylulose 5-phosphate reduced to 2-C-methyl-D-erythritol 4-phosphate by 1-deoxy-D-xylulose 5-phosphate reductoisomerase (Takahashi et al. 1998). The conjugation of 2-C-methyl-Derythritol 4-phosphate and 4-cytidine 5-phosphate leads to the formation of 4-cytidine 5-phospho-2-C-methyl erythritol and the reaction catalyzed by the enzyme 2-C-methylD-erythritol 4-phosphate cytidyltransferase. The 4-cytidine 5-phospho-2C-methyl erythritol converted to 2-C-methyl erythritol 2,4-cyclodiphosphate by the enzyme 2-C-methyl erythritol 2,4-cyclodiphosphate synthase (Rohdich et al. 2000; Steinbacher et al. 2003; Herz et al. 2000; Calisto et al. 2007) (Fig. 1). All the enzymes of the 2C-methyl-Derythritol-4-phosphate pathway are localized in plastids (Hseih et al. 2008; Surie et al. 2000). In the 1-deoxy-Dxylulose 5-phosphate pathway, the synthesis of hydroxymethylbutenyl 4-diphosphate took place from 2-C-methyl erythritol 2,4-cyclodiphosphate and the reaction was catalyzed by hydroxymethylbutenyl 4-diphosphate synthase. The hydroxymethylbutenyl 4-diphosphate directly converted into the isopentenyl diphosphate and dimethylallyl diphosphate mixture by the enzyme isopentenyl diphosphate and dimethylallyl diphosphate synthase (Baker et al. 1992; Cunningham et al. 2000).

In the steps of downstream process, mevalonate converted into IPP, which involves phosphorylations and decarboxylation events. The carried out reactions catalyzed by the following enzymes: mevalonate kinase, phosphomevalonate kinase and mevalonate diphosphate decarboxylase. Although the enzymes involved in these steps are thoroughly studied in yeast and various animal systems, very little information was reported in terms of their biochemical characterization in plants (Gershenzon and Kreish 1999). Recently, a cis-prenyl transferase, neryl phosphate synthase, was reported to provide precursor for monoterpene biosynthesis in several species of Solanum (Schilmiller et al. 2009; Lange and Ahkami 2013). A condensation of one molecule of DMAPP with two molecules of IPP generates farnesyl diphosphate $\left(\mathrm{C}_{15}\right)$, the direct precursor of most sesquiterpenes, which is catalyzed by farnesyl diphosphate synthase. Plant genomes appear to encode various farnesyl diphosphate synthase isoforms that localize to the cytosol, plastids, mitochondria or peroxisomes (Cunillera et al. 1997; Thabet et al. 2011). In tomato, a cis-prenyl transferase, farnesyl diphosphate synthase is localized to plastids of the glandular trichomes, where it is involved in the biosynthesis of sesquiterpene volatiles (Salland et al. 2009). Diterpenes are formed from geranyl geranyl diphosphate which itself is synthesized by the catalysis of geranyl geranyl diphosphate synthase from DMAPP and three molecules of IPP. Isoforms of this enzyme have been reported to occur in plastids, the endoplasmic reticulum and mitochondria (Thabet et al. 2012; Sitthithaworn et al. 2001; Okada et al. 2000; Cheniclet et al. 1992). Terpene synthases often catalyze the formation of multiple products from a prenyl diphosphate substrate, resulting from a catalytic mechanism that involves highly reactive carbocation intermediates (Degenhardt et al. 2009). In general, monoterpene synthases are localized on plastids, whereas sesquiterpene synthases are found in the cytosol (Chen et al. 2011; Aharoni et al. 2003). A mitochondrial localization was determined for a terpene synthase in tomato (Solanum lycopersicum), but the in vivo substrate is currently unknown (Falara et al. 2011). The terpenoid skeletons are further functionized through redox, conjugation and other related reactions (Fig. 1).

The class of triterpenes includes sterols and triterpenoids, which can be synthesized as saponins and sapogenins sufficient amount in plants (Sparge et al. 2004). The linear triterpene squalene is derived from the reductive coupling of the two molecules of farnesyl pyrophosphate (FPP) by squalene synthase. Squalene is later on oxidized biosynthetically by the other enzyme squalene epoxidase to generate 2,3-oxidosqualene. 2,3-oxidosqualene converted to triterpene alcohols or aldehydes by oxidosqualene cyclases (Phillips et al. 2006; Jenner et al. 2005; Haralampidis et al. 2002). In plants, triterpenoid biosynthetic diversity has been developed and their diverse genomes encode multiple oxidosqualene cyclase enzymes to form these triterpene skeletons (Fig. 2). The level at which the structural diversity of triterpenes is generated, depends on the cyclization of 2,3-oxidosqualene by different oxidosqualene cyclases such as lupeol synthase (LS) and $\alpha / \beta$-amyrin synthase (Mangus et al. 2006; Sawai and Saito 2011). All triterpene synthases appear to have diverged from cycloartenol synthase gene (Zhang et al. 2003), but an independent origin for $\beta$-AS in dicots and monocots has also been reported (Phillips et al. 2003; Moses et al. 2013).

The ursolic acid, oleanolic acid and betulinic acid are likely to be derived from $\alpha$-amyrin, $\beta$-amyrin and lupeol, respectively, followed by successive oxidation (Augustin et al. 2011) at the $C_{28}$ position. It has been shown that the triterpene skeletons ( $\alpha$-amyrin, $\beta$-amyrin and lupeol) are cyclized from 2,3-oxidosqualene, a common precursor of 


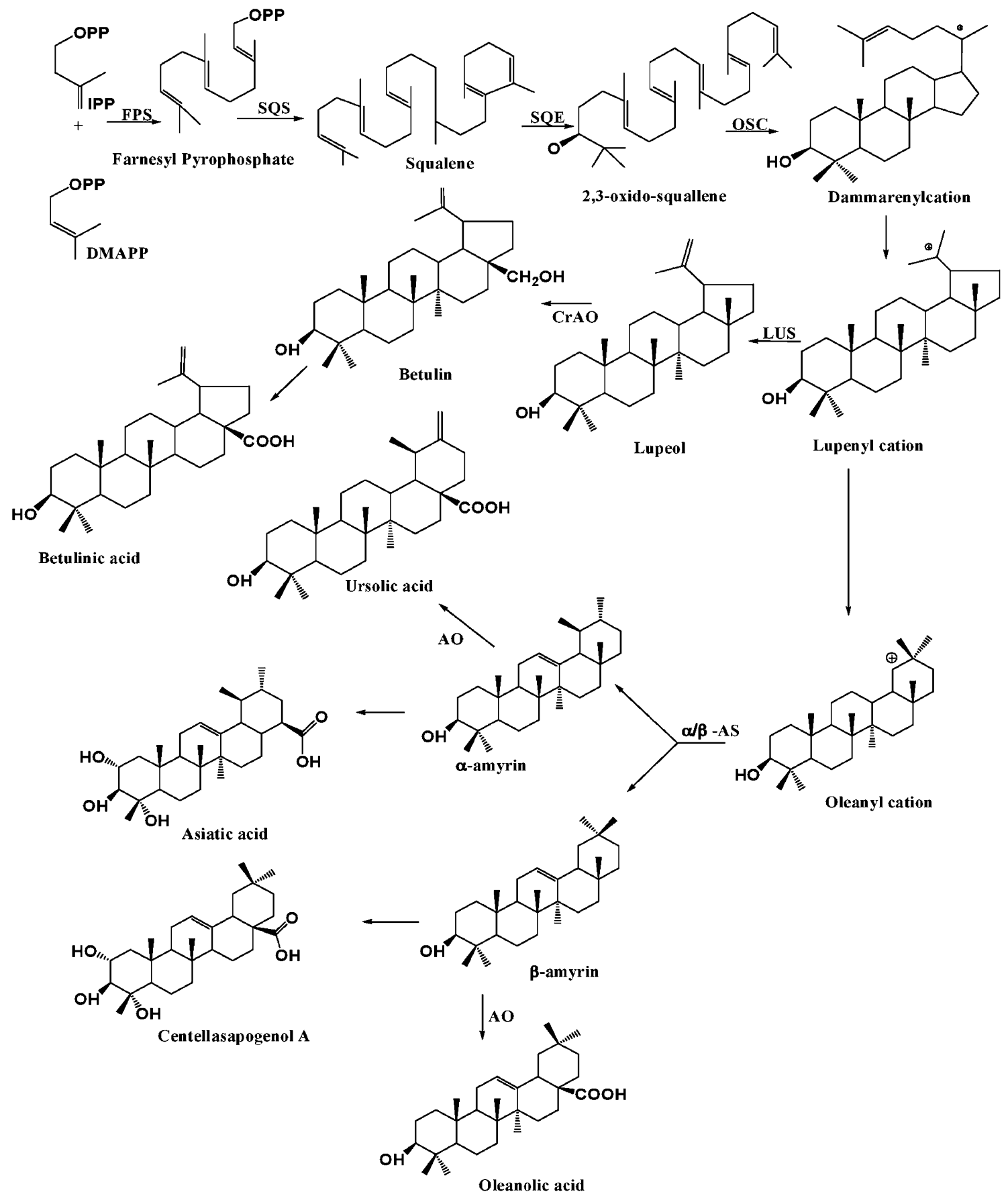

Fig. 2 Schematic overview of triterpenoid biosynthesis. Farnesyl diphosphate synthase (FPS) isomerizes isopentenyl diphosphate and dimethylallyl diphosphate (DMAPP) to farnesyl diphosphate, while squalene synthase converts to squalene. Squalene epoxide oxidizes the squalene to 2,3-oxidosqualene. Oxidosqualene cyclase (OSC) catalyzes 2,3-oxidosqualene through cationic intermediates to one or

phytosterols and triterpenoids (Abe et al. 1993). Oxidosqualene cyclases yielded one specific product, such as lupeol synthase (Shibuya et al. 1999; Guhling et al. 2006; Moses et al. 2013), $\beta$-amyrin synthase (Kushiro et al. 1998; Kirby et al. 2008; Shibuya et al. 2009) and $\alpha$-amyrin more cyclic triterpene skeletons. The other enzymes involved in the biosynthesis include $\alpha / \beta$ amyrin synthase $(\alpha / \beta$ AS) which can also form the lupenyl cation but further ring expansion and rearrangements are required before the deprotonation to $\alpha / \beta$ amyrin, the precursors of sapogenins. $\alpha$-Amyrin oxidase involved in biosynthesis of ursolic acid and oleanolic acid

synthase (Muffler et al. 2011), cycloartenol synthase (Hayashi et al. 2000) and cucurbitadienol synthase (Shibuya 2004). Following the formation of the carbon skeletons, the triterpene alcohols are modified by various cytochrome P450s, dehydrogenases, reductases and other 
modification enzymes, while some triterpenoids are synthesized in all plant cells. Laticifers are elongated epithelial cells that produce chemically complex latex, which can consist of a polyterpenoids such as natural rubber (Beilen and Poirier 2007). Trichomes which are glandular in nature, are generally the known as storage organs of terpenoids and/ or phenolic compounds (Lange and Turner 2013).

The synthesis of isopentenyl diphosphate and dimethylallyl diphosphate, both are intermediates of terpenoid biosynthesis, is compartmentalized. The mevalonic acid pathway operates in cytosol, which is responsible for the formation of sesquiterpenes and sterols; 1-deoxy-D-xylulose 5-phosphate (DXP/MEP) pathway operates in the plastids, involved in the synthesis of monoterpenes, diterpenes and some sesquiterpenes as well as plastoquinones (Laule et al. 2003). In plants, mevalonic acid pathway's enzyme localization is also fragmented. The 3-hydroxy-3methylglutaryl $\mathrm{CoA}$ reductase and squalene synthase are localized in the endoplasmic reticulum (Leivar et al. 2005; Sapir-Mir et al. 2008; Busquets et al. 2008) while the acetoacetyl $\mathrm{CoA}$ is also important enzyme of mevalonic acid pathway, localized in peroxisomes (Reumann et al. 2007). In contrast, the DXP pathway enzymes are localized in plastids of cyanobacteria (Ginger et al. 2010). However, after constant observations of certain uncertainties, it has been widely accepted that initial reactions of DXP pathway are catalyzed in the cytosol while remaining reactions operated in the plastid. In red algae and the Cyanophora paradoxa, both mevalonic acid and DXP pathway run concurrently (Grauvogel and Peterson 2007). However, it has been proved that both the pathways are not separated spatially. The taxol (sesquiterpenes) is synthesized by the both mevalonic and DXP pathways (Adam and Zapp 1998; Wang et al. 2003). The unidirectional proton symport system of export of terpenoid intermediates and their involvement between cytosol and plastid pathway have been proved by the $\mathrm{Ca}^{2+}$ gated channel (Bick and Lange 2003). Laule et al. (2003) have suggested in their experiment that some limiting plastidial membrane transporters must be operated in the exchange of terpenoid intermediate's exchange in between cytosol and plastid (Liao et al. 2006).

\section{Defense responses of terpenoids in plants}

Plant kingdom has direct and indirect defense responses when they come in contact of microbial pathogens. The direct mode of defense mechanism includes physical structures like as trichomes, thorns as well as accumulation of phytochemicals that have antibiotic activities. The compounds such as phytoalexins are low-molecular-weight compounds that are produced as part of plant defense mechanisms. In few plant species the diterpenes and sesquiterpenes act as phytoalexins, e.g., 14 diterpene phytoalexins have been investigated from Oryza sativa. These phytoalexins can be grouped into four types-monilactones A and B (Hwang and Sung 1989), oryzalexins A-F (Peters 2006) and oryzalexin S (Tamongani and Mitani 1993). Polycyclic diterpenoids are synthesized from geranyl geranyl diphosphate via the intermediate hydrocarbon precursors (e.g., 9- $\beta$-pimara-7, 15-diene, stemar-13-ene, entsandaracopimaradiene and ent-cassa-12, 15-diene). All these natural products are accumulated in leaves in response to inoculation with the pathogenic blast fungus, Magnaporthe grisea, or ultraviolet irradiation and exhibit antimicrobial properties (Prisic et al. 2004).

Indirect mode of defenses indicates that the plants have characteristics to defend against herbivores indirectly by enhancing the effectiveness of natural enemies of the herbivores. One of the most amazing examples of the plant indirect defense is the release of the blend of specific volatiles, which attract the carnivores of herbivores, after herbivore attacking. More attention has been paid in case of corn, lima bean, poplar and cotton that are well studied with genetics, biochemical, physiological and ecological approaches (Rodriguez-Saona et al. 2003; Arimura et al. 2004a; Mithofer et al. 2005; Schnee et al. 2006). In an olfactometer assay, the transgenic Arabidopsis plants used as odor sources, females of the parasitoid Cotesia marginiventris learned to exploit the TPS10 sesquiterpenes to locate their lepidopteran host (Schnee et al. 2006). When a strawberry nerolidol synthase gene was expressed in Arabidopsis transgenic plants emitted two new terpenoids $(3, \mathrm{~S})-(E)$-neridol and its derivative $(E)$-4,8-dimethyl-1,3-7nonatriene $[(E)$-DMNT] and attracted more carnivorous predatory mites (Kappers et al. 2005). The capacity to produce deterrents to insects from plant-derived terpenoids is typical of some Chrysolina species. Because feeding of herbivores alters the aromatic profile of essential oil-producing plants like Mentha aquatica, the issue is both economically and ecologically relevant (Burse et al. 2009; Atsbaha Zebelo et al. 2011).

Airborne terpenoids are also critical components of plant defense responses to abiotic and biotic stresses (Unsicker et al. 2009; Vickers et al. 2009). From agronomic perspective, crop losses due to insect infestation are a significant issue (El-Wakeil et al. 2010). Insecticide applications are most common and effective strategy for control of insects, but some of the agrochemicals have undesirable side effects on useful insects and can pose long-term risks to the environment (Dedryver et al. 2010; Zulak and Bohlmann 2010).

When patchoulol synthase (PTS), a sesquiterpene synthase from Pogostemon cabli L., was targeted to the 
cytosol in transgenic tobacco (Nicotiana tabacum L. cv. Xanthi), only small amounts of the expected product, patchoulol, were detected. When the same gene was expressed coordinately with an additional copy of farnesyl diphosphate synthase, the patchoulol accumulation in transgenic tobacco also remained very low (Wu et al. 2006), while both gene products patchoulol synthase and farnesyl diphosphate synthase were targeted to plastids, a patchoulol accumulation was increased, which appeared to be volatilized. It was also observed that volatile emitted from these transgenic plants significantly deterred tobacco hornworms and pine beetles from feeding on leaves $(\mathrm{Wu}$ et al. 2006; Bohlmann 2012).

\section{Plant terpene synthases}

The investigations of terpene synthases have been an interesting and active area of plant metabolic engineering research and may genes have been isolated from various plant species (gymnosperms and angiosperms), including Picea abies (Martin et al. 2004), Taxus media (Wildung and Croteau 1996), Arabidopsis thaliana (Chen et al. 2003; Degenhardt et al. 2009), Cucumis sativus (Mercke et al. 2004), and Nicotiana attenuata (Facchini and Chappel 1992). The total numbers of terpene synthases reported from Thapsia laciniata are 8 monoterpene and 5 sesquiterpene (Drew et al. 2013) which are slightly larger than the number reported in Arabidopsis thaliana and Artemisia annua (Tholl and Lee 2011). Several sesquiterpene synthases have also been cloned and characterized from maize (Kölner et al. 2004). In general, the lengths of monoterpene synthases are between 600 and 650 amino acid residues and are 50-70 amino acids are larger than sesquiterpene synthases (Martin et al. 2004). Most diterpene synthases are approximately 210 amino acids longer than monoterpene synthases because of an additional internal element that is conserved in both sequence and position (Prisic et al. 2004). All the terpene synthases contain the aspartate-rich DDxxD motif involved in the coordination of divalent metal ions for substrate binding (Lesburg et al. 1997). The terpene synthases are further sub-classified into four subfamilies-TPSa, TPSb, TPSd and TPSg. The TPSa family consists of angiosperm terpene synthases (Bohlmann et al. 1998; Dudareva et al. 2003), the TPSb family contains angiosperm monoterpene synthases (Bohlmann et al. 1998; Dudareva et al. 2003), the TPSb includes angiosperm monoterpene synthases (Bohlmann et al. 1998; Dudareva et al. 2003), TPSd of gymnosperm monoterpene synthases (Bohlmann et al. 1998; Dudareva et al. 2003) and TPSg Antirrhinum majus monoterpene synthases (Bohlmann et al. 1998; Chen et al. 2003) also share common evolutionary origin.
The triterpene synthases lead to synthesis of tricyclic, tetracyclic and pentacyclic molecules in complex of concerted reaction steps catalyzed by single enzyme. The sterol and triterpenoid biosynthetic pathways diverged at some point, depending on the involvement of the type of the oxidosqualene synthases. Cyclization of 2,3-oxidosqualene in the chair-boat-chair conformation leads to protosteryl cation intermediate, sterol precursor, via the synthesis of cycloartenol or lanosterol in plants (Kolesnikova et al. 2006; Suzuki et al. 2006), while in contrast to 2,3-oxidosqualene in the chair-chair-chair conformation is cyclized into a dammarenyl carbocation intermediate, which subsequently gives rise to diverse triterpenoid skeletons after further re-arrangements. Many different types of oxidosqualene synthases have been isolated from various plant species including lanosterol synthase (Baker et al. 1995; Sung et al. 1995), cycloartenol synthase (Bach 1995; Kawano et al. 2002), lupeol synthase (Hayashi et al. 2004; Segura et al. 2000) and $\beta$-amyrin synthase (Hayashi et al. 2001; Iturbe-Ormaetxe et al. 2003). Besides these synthases, some multifunctional triterpene synthase have also been characterized from other different plant species (Basyuni et al. 2006; Shibuya et al. 2007).

\section{Phylogenetic analysis of terpenoid synthases}

On the basis of the phylogeny, the gymnosperm terpene synthases have been subdivided into three distinct cladesTPS-d1 to TPS-d3. The TPS-d1 subclade are $(-)-\alpha / \beta$ pinene synthases, (-)-linalool synthases and $(E)$ - $\alpha$-farnesene synthases; in TPS-d2 clade are longifoline synthase and in TPS-d3 clade are levopimaradiene/abietadiene synthases and isopimaradiene synthase (Martin et al. 2004). The functional identification of spruce terpene synthase genes account for several terpenoid compounds of the oleoresin and volatile emissions. Many terpene synthase genes $(T P S d)$ of terpenoid metabolism, especially entcopalyl diphosphate synthase and ent-kaurene synthase gene appear to be expressed as single copy genes (Bohlmann et al. 1999). These primary metabolism terpene synthase genes are basal to the specialized metabolism genes and are the descendants of an ancestral plant diterpene synthase similar to the non-vascular plant as Physcomitrella patens (Hayashi et al. 2006; Keeling et al. 2010, 2011).

Sesquiterpene synthases sequence of roots of Cycus species was investigated and it was found that gymnosperms form a distinct group from the angiosperms, which displayed a pattern that seemed to be influenced by the types of products of different plant species. By the phylogenetic analysis, it can be predicted that $\alpha$-copaene synthase gene is more homologous to germacrene $B$, 
germacrene D and valencene synthase gene (Hiltpold and Turlings 2008; Wen et al. 2012). A sesquiterpene synthase gene that produces $\alpha$-copaene as its sole reaction product has been reported. This enzyme is highly expressed in potato and correspondence to the difference in tuber flavor between two cultivars of potato (Ducreux et al. 2008; Zapta and Fine 2013).

The terpenoid synthases of primary metabolism, (-)CDP synthase (Sun and Kamiya 1994; Ait-Ali et al. 1994; Bensen et al. 1995) and kaurene synthase B (Yamaguchi et al. 1996), are only distantly related to those of secondary metabolism, including members of sub-families TPSa, TPSb and TPSd. However, all plant terpene synthases share a common evolutionary origin and it appears that the bifurcation of terpenoid synthases of primary and secondary metabolism occurred before separation of angiosperms and gymnosperms. Terpene synthases of secondary metabolism constitute the most extensively studied TPS sub-families including TPSa, TPSb, TPSd and the distant and possibly ancient TPSf branch containing linalool synthase (Bohlmann et al. 1998; Chen et al. 1996). Valencene synthase (Sheron-Asa et al. 2003) and 5-epi aristolochene synthase (Back and Chappel 1996) are related to one another based on the biosynthesis of sesquiterpenes within the eremophilene class of compounds. The Magnolia possesses a single intron positioned near the $5^{\prime}$ region of the gene, similar to the first intron in all other three classes of terpene synthases from plants. The intron found in fungal trichodiene synthase gene is inserted into the middle of the trichodiene synthase gene and is not spatially oriented similar to the insertion site of the first intron in any of the plant genes including $M g 25$ (Trapp and Croteau 2001; Lee and Chappel 2008). The dendrogram analysis was conducted to determine the evolutionary relatedness of chamomile terpene synthases to those of others Asteraceae. MrTPS1, MrTPS2, MrTPS3 and MrTPS5 were found to belong to the TPSa sub-family covering angiosperms, whereas MrTPS4 fell into the TPSb sub-family covering angiosperm monoterpene synthases (Irmisch et al. 2012). The monoterpenes are formed in plastids and the nucleusencoded monoterpene synthases are targeted by $\mathrm{N}$-terminal transit peptides of approximately 40-70 amino acids which reside upstream of the conserved RRx8W motif and are cleaved during import from the nucleus. (Williams et al. 1998; Turner et al. 1999). In contrast to the multiple closely related AtTPS of the TPSa and TPSb groups, only one AtTPS member is found in each of three sub-families TPSc, TPSe and TPSf (Arabidopsis thaliana terpene synthases). The copalyl diphosphate synthases show between 45 and $55 \%$ identity. The AtTPS GA2 enzyme (Yamaguchi et al. 1998) is a diterpene synthase of the TPSe subfamily of kaurene synthases. Finally AtTPS04 has a TPSf type primary structure reminiscent of that of linalool synthase from Clarkia breweri (Dudareva et al. 1996). It has been suggested that AtTPS04 is an orthologue of this linalool synthase in Arabidopsis thaliana (Cseke et al. 1998; Aubourg et al. 2002). The comparison of Grtps (grape fruit terpene synthases) amino acid sequence with the sequences of other terpene synthase indicated that this Grtps cDNA is truncated at the $5^{\prime}$ terminus and that the truncation represents 18 amino acid residues of the presumptive transit peptide region at the $\mathrm{N}$-terminus of the deduced protein. The peptide is found in both monoterpene and diterpene synthases and supposedly facilitates the import of these nuclear encoded gene products into plastids, a process that involves cleavage of the preproteins to the mature active enzymes (Mau and West 1994; Vogel et al. 1996; Jia et al. 2005). The phylogenetic analysis of large number of Vitis vinifera terpene synthase genes resolved a bifurcation of TPSb and TPSg sub-families at a juncture that was previously ambiguous and had misclassified some TPSg genes as TPSb members. Later on it was concluded that grapevine geraniol and linalool synthase matches with basil geraniol and linalool synthase and showed same proximity which indicates that these TPS functions already existed have evolved from same ancestor (Martin et al. 2010).

Azadirachta indica and Citrus belong to the order $\mathrm{Ru}-$ tales and the phylogenetic studies reaffirmed their taxonomic closeness. Additionally, phylogenetic studies grouped A. indica with Melia species, one that is also known to harbor bioactive compounds suggesting a common evolutionary process with regard to synthesis of these compounds in Meliaceae. The repeat analysis showed low repeat content in A. indica genome compared with other sequenced angiosperms. This could have been due to presence of xenobiotic terpenoids specific to the plant, which might have been a major impediment for horizontal gene transfer (Richardson and Palmer 2007; Krishnan et al. 2012). The phylogenetic analysis of cycloartenol synthase, lupeol synthases and the dicot $\beta$-amyrin synthase reported them as multifunctional enzymes. These enzymes have same specificity clusters by which authors have suggested a molecular evolution mechanism for lupeol synthase and $\beta$ amyrin synthase arising from a common ancestral cycloartenol synthase (Shibuya et al. 1999; Zhang et al. 2003).

The increasing diversification of the cyclization reaction sequence from the dammarenyl to the oleanyl cation via the lupenyl cation is consistent with this evolutionary scheme. MdOSC1, MdOSC2 and MdOSC3 are located with in the group of enzymes that produce a dammarenyl cation intermediate in Malus domestica. In MdOSC1 and MdOSC3 cluster, lupeol synthases are more related to $\beta$ amyrin synthases than to lupeol synthases (Basyuni et al. 2007; Guhling et al. 2006; Brendolise et al. 2011). This new class of lupeol synthase includes BgLUS, RcLUS and 
multifunctional triterpene synthase KcMS and another putative OSC (EtOSC-Euphorbia terucalli triterpene synthase) for which no triterpene synthase activity has been detected when it is expressed in yeast (Kajikawa et al. 2005).

The phylogenetic analysis using neighbor-joining methods showed that SITTS1 and SITTS2 (Solanum lycopersicum) terpene synthases are more closely related to each other than to any other oxidosqualene cyclases and they together with the Panax ginseng $\beta$-amyrin synthases (Kushiro et al. 1998) form the subclad within a group of oxidosqualene cyclase enzyme that were all characterized as $\beta$-amyrin synthases from different plant species. The intron patterns and exon lengths of the two SITTS1 genes are very similar to those of the other oxidosqualene cyclases, while S1TTS2 gene organization most closely resembles OSC3 of Lotus japonicus (Sawai et al. 2006; Wang et al. 2011). The close match in localization of transcripts and metabolites makes it very likely that S1TTS1 and S1TTS2 genes dedicated entirely making the triterpenoids destined for the cuticular wax of the fruit surface. This major biological function can be assigned to the OSCs; the cuticular triterpenoids contribute significantly to the chemical composition and to the ecophysiological properties of the fruit cuticle (Vogg et al. 2004; Isaacson et al. 2009). It should be noted that similar biological functions had previously been attributed to a few other OSCs, for example, a glutinol synthase and a friedelin synthase from Kalanchoe daigremontiana (Wang et al. 2010).

It has been reported that 13 Arabidopsis thaliana OSC genes and the 11 triterpene synthase genes are grouped into one functional group. Furthermore, 20 out of 36 Poaceae OSC genes were also assigned either to the pentacyclic triterpene synthase-like group based on the characterized $\beta$-amyrin synthase from Avena species (Haralampidis et al. 2001; Qi et al. 2004) or to the rice isoarborinol synthase group (Xue et al. 2012). In Arabidopsis thaliana, a tandem cluster on chromosome 1 containing four homologous $O S C$ genes, Atlg78950, Atlg78955/CAMS1, At1g78960/LUP2 and At1g78970/LUP1, is likely to have arisen by three tandem duplication events. Another tandem duplicate gene pair At4g15340 and At4g15370, encoding arabidiol synthase and baruol synthase, respectively (Xiang et al. 2006; Lodeiro et al. 2007), is located on A. thaliana chromosome 4. Indeed, most triterpene synthase genes in the Poaceae family appear to have arisen from $C S$ genes by the D3 gene duplication event, which caused the divergence of the 20 triterpene synthase genes (D3-2) from 12 CS genes and other closely related genes form group D3-1. The D3 duplication event is highly likely to have been a tendem duplication that occurred during the ancient Poaceae genome before the $\rho$ whole genome duplication, which was estimated to have occurred between 117 and 50 mya (Gaut 2002; Yu et al. 2005; Lescot et al. 2008; Jaio et al. 2011).

In pairwise comparison of all predicted Citrus terpene synthases with all Arabidopsis AtTPS proteins, it was found that the overall sequence identity varies widely from 18 to $91 \%$. Citrus terpene synthase EST contigs were long enough to allow the complete encoded protein sequences to be deduced (ranged from 547 to 617 amino acids), which corresponds to the size of known monoterpene synthases, sesquiterpene synthases and diterpene synthases of secondary metabolism (Bohlmann et al. 1998; Aubourg et al. 2002). Most terpene synthases encoded by class-III genes contain variations of a conserved motif RR(x)8W, close to the N-terminus (Dornelas and Mazzafera 2007).

2-Methyl-3-buten-2-ol (MBO-hemiterpene) is a fivecarbon alcohol produced and emitted by plant species of pine in large quantities. The gene most closely related to MBO synthase is a linalool synthase from Picea abies with which MBO shares $82 \%$ amino acid identity. Also closely related to MBO synthase are farnesene synthase from $P$. abies and $P$. taeda. These enzymes form a strongly supported clade of related enzymes producing MBO, linalool and $E$ - $\alpha$-farnesene nested within what is otherwise a clade dominated by enzymes producing cyclic monoterpene (Gray et al. 2011). MBO synthase and isoprene synthase comparison clearly demonstrate that hemiterpene synthase evolved independently in gymnosperms and angiosperms. The MBO synthase clusters with gymnosperm monoterpene synthase, isoprene clusters with angiosperm monoterpene synthases and these gene families diverged between 250-290 million years ago (Martin et al. 2004).

\section{Regulation of terpenoid biosynthesis}

The role of light and temperature in modulating a range of terpenoids and the corresponding transcripts has been reported, but there is no universal behaviour and it varies depending upon the type of metabolites as well as plant species. The 3-hydroxy-3-methylglutaryl CoA reductase is stimulated by light in Triticum aestivum (Aoyogi et al. 1993), pea (Wong et al. 1982) and potato (Korth et al. 2000), but down-regulated by light in Lithospermum erythrorhizon (Lange et al. 1998). The effects of light as promoter on 3-hydroxy-3-methylglutaryl CoA reductase activity has been documented and also the light-mediated alteration in 3-hydroxy-3-methylglutaryl CoA reductase transcripts (Learned and Connolly 1997; Kawoosa et al. 2010). Rodrìguez-Concepción (2006) suggested about the light-dependent regulation of terpenoid biosynthesis during the early stages of development in Arabidopsis thaliana. As per their model, the seedlings which were grown in the dark obtain lower level of precursors for the synthesis of 
sterols from the mevalonic acid pathway. Some of the prenyl diphosphates of the mevalonic acid pathway might be translocated to the plastid for the synthesis of carotenoids and gibbrellins; while those seedlings were grown in the light, the activity of mevalonic acid pathway increased and the isoprenoid precursors are not required by the plastid (Vranova et al. 2012). In Artemisia апnиa, the discharging of $\beta$-pinene fluctuates as per the rhythm of day as well as night and it is higher in the day light than night (Lu et al. 2002). The all terpenoid compounds of Arabidopsis thaliana flowers showed clear diurnal emission patterns (Aharoni et al. 2003).

Jasmonate was reported to be general inducer of biosynthesis of plant secondary metabolite (Memelink et al. 2001; van der Fits and Memelink 2000). Jasmonate and its derivative methyl jasmonate were shown to induce the terpenoid indole biosynthesis in suspension cell cultured with auxin and to enhance the terpenoid indole alkaloid production when cells were cultured in an auxin-free medium (Gantet et al. 1998). Genes involved in secologanin biosynthesis ( $\mathrm{Crdxs}, \mathrm{Crcpr}$ ) were upregulated by methyl jasmonate as well as most of the known other genes of terpenoid indole alkaloid biosynthesis pathway (Hedhili et al. 2007; Siamaru et al. 2007; Zhao et al. 2004). Downstream of the conserved jasmonate hormone perception and initial signaling cascade, species-specific transcriptional machineries exist that regulate the transcriptional activity of specific biosynthetic genes (Pauwels et al. 2009; Pauwels and Goosens 2011). A few transcriptional factors regulated by the jasmonate hormone signaling cascade that activate the transcription of sesquiterpenoid biosynthetic genes have already been reported (De-Geyter et al. 2012). The triterpenoid contents in Ocimum basilicum was produced higher in quantity after the treatment with methyl jasmonate rather than control plants. The exogenous treatment of methyl jasmonate affected the production of terpenoids by regulating the terpene synthase genes ( $\mathrm{Li}$ et al. 2007; Prins et al. 2010).

It is well known that the monoterpene synthase gene SIMTS1 activity is induced by jasmonic acid (van Schie et al. 2007). The jasmonic acid has been shown to increase trichome density on newly formed leaves of Arabidopsis and tomato (Boughton et al. 2005; Traw and Bergelson 2003). The production of acyl sugars on the leaf surface of Datura wrightii plants increased without affecting trichome density (Hare and Walling 2006). The expression levels of most of the genes of the mevalonic acid pathway and monoterpene or sesquiterpene synthesis follow the same profile during development, suggesting coordinated regulation of terpenoid biosynthesis at the gene level. However, although expression of these genes is relatively trichome specific, the expression profiles do not alter metabolic accumulation during development, suggesting that terpenoid synthesis is not regulated at the transcript level in tomato trichomes but rather involves other (post-transcriptional) regulatory mechanisms. Similarly, only a loose correlation between terpenoid pathway gene expression and enzyme activity has been found in Ocimum basilicum terpenoid metabolism (Iijima et al. 2004; Besser et al. 2008). Jasmonic acid is essential for induction of defenses in glandular trichomes. Production of many trichome metabolites is also regulated tightly by transcriptional control, thereby allowing for temporally regulated emission of plant volatiles (Dudareva et al. 2006; Glas et al. 2012).

Methyl jasmonate is a cyclopentanone ring bearing lipophilic hormone synthesized in plants from octadecanoid pathway and they play role in development of responses to biotic stress (Creelman and Mullet 1997). The changes in accumulation of terpene synthase transcripts were also observed in methyl jasmonate-treated Norway spruce; this supports the view that the transcription of terpene synthase genes also regulated by this hormone (Fäldt et al. 2003). The accumulation of taxoid (diterpene taxadiene) was enhanced by supplementation of methyl jasmonate in cell cultures of Taxus (Ketchum et al. 1999; Phillips et al. 2006). Traumatic ducts are specialized anatomical structures for the accumulation of resin terpenes, which are formed in Norway spruce and other conifer plants. Like other resin ducts, traumatic ducts are lined with epithelial cells thought to be the site of terpene biosynthesis. The development of traumatic ducts in xylem of Norawy spruce, induced by the treatment of methyl jasmonate was similar in fashion, which caused by the attack of fungal elicitation and mechanical wounding (Krokene et al. 2008; Herrera et al. 2005; Martin et al. 2002). The morphological changes are accompanied by an increase in monoterpene and diterpene synthase activity peaking at the highest rate at 10-15 days after treatment of methyl jasmonate (Martin et al. 2002). The significant increase in the resin terpenoid quantity in bark and wood of Norway spruce followed by methyl jasmonate treatment has also been reported (Martin et al. 2004; Miller et al. 2005).

The level of mRNAs of squalene synthase and $\beta$-amyrin synthase was upregulated by adding methyl jasmonate to Glycyrrhiza glabra cell cultures and it was observed that the level was higher 3 days after the treatment and lasted for 7 days. The mRNA levels of cycloartenol synthase and oxidosqualene cyclase, which are involved in the biosynthesis of phytosterols, were relatively constant (Hayashi et al. 2003). Artemisia annua plants treated with methyl jasmonate showed only slight change in the transcription levels of the control plants. 3-hydroxy-3-methylglutaryl CoA reductase gene expression decreased 1.5 -fold at $24 \mathrm{~h}$ and then increased threefold by $48 \mathrm{~h}$ (Mehjerdi et al. 2013).

When the zeatin and ethylene were added together to the culture medium of Catharanthus roseus cell cultures, the 
mRNA level of mevalonic acid pathway genes coordinately increased in suspension culture cells (Papon et al. 2005). In addition, the zeatin stimulates the bioconversion of exogenic secologanin to the terpenoid indole alkaloid ajmalicine, suggesting that cytokinin may also act on other downstream enzymatic steps of the terpenoid indole alkaloid biosynthesis pathway (Decendit et al. 1992). Similarly, the ethylene treatment itself induces the formation of traumatic ducts in Pseudotsuga menziesii and Sequoiadendron giganteum (Hudgins and Franceschi 2004) and stimulates the accumulation of $\beta$-thujaplicin in $C$. lusitanica at low levels (Phillips et al. 2006).

Dudareva et al. (2003) reported that the biosynthesis and emission of the monoterpenes $(E)$ - $\beta$-ocimene and myrcene in Antirrhinum majus flowers correlate with specific expression patterns of the lobes of flower petals during floral development, with the highest transcripts levels detected at day four post anthesis. In Arabidopsis flowers, monoterpene and sesquiterpene synthases are not expressed in flower petals; instead their expression is limited to the stigma, anthers and sepals (Tholl et al. 2005). Many monoterpene and sesquiterpene synthase genes have been reported from terpene accumulating cells and tissues such as leaf glandular trichomes of Citrus and grapes (Picaud et al. 2005; Lücker et al. 2004; Shimada et al. 2004; Kai et al. 2006). Most of the terpene synthase genes belonging to TPSa and TPSb sub-families reached the highest expression in accordance with the peak of accumulation of the respective compounds, while in TPSg sub-family, only one gene for linalool synthase showed major transcript in the ripening of berries. The geraniol synthase had a peak of expression that started to increase and overcome the linalool concentration (Matarese et al. 2013; Chen et al. 2011; Falara et al. 2011).

Ginsenoside backbones are synthesized via the isoprenoid pathways where squalene acts as precursor. The squalene is synthesized by a series of several reactions with geranyl diphosphate synthase, farnesyl pyrophosphate synthase and squalene synthase through mevalonate pathway (Kuzuyama 2002) and subsequent reactions with squalene epoxidase yielded 2,3-oxidosqualene (Fig. 3). The cyclization of 2,3oxidosqualene into dammarenediol and $\beta$-amyrin is catalyzed by oxidosqualene cyclases including dammarenediolII synthase and $\beta$-amyrin synthase (Han et al. 2006, 2010; Tansakul et al. 2006; Kim et al. 2010). Both glycyrrhizin and soyasaponins share a common biosynthetic intermediate, $\beta$ amyrin (Fig. 3), which is synthesized by $\beta$-amyrin synthase, an oxidosqualene cyclase (OSCs). OSCs catalyze the cyclization of 2,3-oxidosqualene, a common intermediate of both triterpene and phytosterol biosynthesis (Abe et al. 1993; Haralampidis et al. 2002). In Glycyrrhiza glabra three OSCs: $\beta$-amyrin synthase, lupeol synthase and cycloartenol synthase are situated at the branching step for biosynthesis of oleanane-type triterpene saponins, lupane-type triterpene (betulinic acid) and phytosterol, respectively (Fig. 4). cDNAs of $\beta$-amyrin synthase (Hayashi et al. 2001) and cycloartenol synthase (Hayashi et al. 2000) have already been isolated from cultured cells of licorice (Kölner et al. 2004; Hayashi et al. 2003).

Terpenoid biosynthesis occurs within specific tissues or at specific stages of development in plants (Nagegowda 2010; Vranova et al. 2012). In many plant species those have glandular trichomes, specialized structures for secreted terpenoid natural products (Lange and Turner 2013). The glycyrrhizin accumulates only in underground organs, stolons and roots of licorice plants (Seki et al. 2008). Avenacins, the bioactive saponins in Avena sativa accumulate only in epidermis of roots, where they develop resistance to plant pathogenic fungal organisms (Haralampidis et al. 2001). The biosynthesis of avenacin genes are co-regulated and exclusively expressed in the epidermis of roots in which the avenacins are accumulated (Qi et al. 2006; Field and Osbourn 2008).

Sometimes the regulation of terpenoid biosynthesis is induced by herbivore feeding, attack by pathogen or abiotic stresses (Nagegowda 2010; Vranova et al. 2012). The enhancement of concentration of terpenoids in response to various abiotic stresses is often is mediated by an increase in transcriptional activity of the specific terpenoid biosynthetic genes (Tholl 2006; Nagegowda et al. 2004, 2010; Xi et al. 2012). This type of transcriptional response is controlled by complex signaling cascade in which jasmonate hormone play important role. The pathogen attack causes transcriptional and metabolic changes in plant cell cultures of Medicago sativa (Suzuki et al. 2005). The defence mechanismrelated synthesis of terpenoids has been studied by various authors (Van Poecke et al. 2001; Rodriguez-Saona et al. 2003). The synthesis of several terpenoids in poplar is induced and emitted from the Malacosoma disstria infested leaves (Arimura et al. 2004a). Tetranychus urticae infests on the Lotus japonicas and after this it induces the emission of the $(E)$ - $\beta$-ocimene and also accumulation of $(E)$ - $\beta$-ocimene synthase gene transcript (Arimura et al. 2004b).

In addition to the transcriptional, developmental and spatiotemporal modulation of terpenoid biosynthetic genes, the post-translational regulation mechanisms were also reported in the biosynthesis of terpenoids. The HMGR activity, the specific enzyme that catalyzes crucial regulatory steps of the mevalonic acid pathway, is controlled at the protein level through the activity of protein phosphatase A or by the E3 ubiquitin ligase SUD1 (Leivar et al. 2011; Doblas et al. 2013). The role of jasmonic acid in the induction of trichome-specific terpene synthases has been well reported (van Schie et al. 2007). Upon perception of pathogens or herbivores, signal transduction pathways are activated, which lead to induced defense responses. 
Fig. 3 Biosynthetic pathways of ginsenosides from squalene in $P$. ginseng<smiles>CC(C)=CCCC1=CCCC(CO[Na])C1CC/C=C(\C)CC/C=C(\C)CCC=C(C)C</smiles><smiles>COC[C@@H]1CC2C(CC[C@]3(C)C2C[C@H](O)[C@@]2(C)C(C)(C)[C@@H](O)CC[C@]32C)C1[C@@](C)(O)CCC=C(C)C</smiles><smiles>CC(C)=CCCC(C)=CCCCC1=C(C)CCC=C1CCC1CC1(OC(=O)OCc1ccccc1)C(C)(C)C</smiles>

Protopanaxatriol

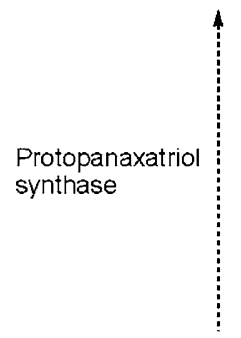

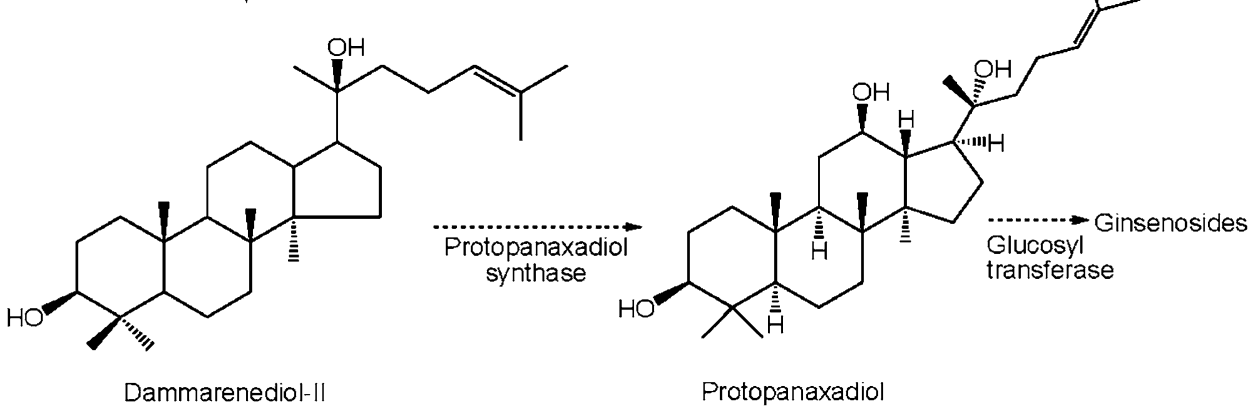

\section{Terpenoids under clinical trials}

Terpenes are the largest group of natural bioactive compounds including monoterpenes, sesquiterpenes, diterpenes, hemiterpenes and triterpenes. Out of these natural compounds, several terpenes are under studies of clinical trials, which are as follows:

\section{D-Limonene}

Monoterpenes such as D-limonene and peryl alcohol prevent mammary, live and other types of cancers. The monoterpenes have several cellular and molecular activities that could potentially underlie their positive therapeutic index. The monoterpenes inhibit the isoprenylation of small $G$ proteins. Such inhibitions could alter signal transduction and result in altered gene expression. When mammary cancers were initiated in rats by either the direct acting carcinogen $N$-methyl- $N$-nitrosourea or indirectly acting carcinogen DMBA, they could be prevented from developing if the carcinogen-exposed rats were fed D-limonene (Elson et al. 1988; Yoon et al. 2010).

D-Limonene is considered to have fairy low toxicity. It has been tested for carcinogenicity in mice and rats. Although initial results showed D-limonene increased the incidence of renal tubular tumours in male rats, female rats and mice in both genders showed no evidence of any tumor. Subsequent studies have determined how these tumors occur and established that D-limonene doses pose mutagenic or nephrotoxic risks to humans as well as human prostate cancers. In humans, D-limonene has demonstrated toxicity after single and repeated dosing for up to 1 year. Being a solvent of cholesterol D-limonene has been used to clinically to dissolve cholesterol containing gallstones (Igimi et al. 1991; Rabi and Bishayee 2009a, b). Because of its gastric acid neutralizing effect and its support of normal peristalsis, it has been also used for relief of heartburn and gastroesophageal reflux (Kodama et al. 1976; Sun 2007). In 


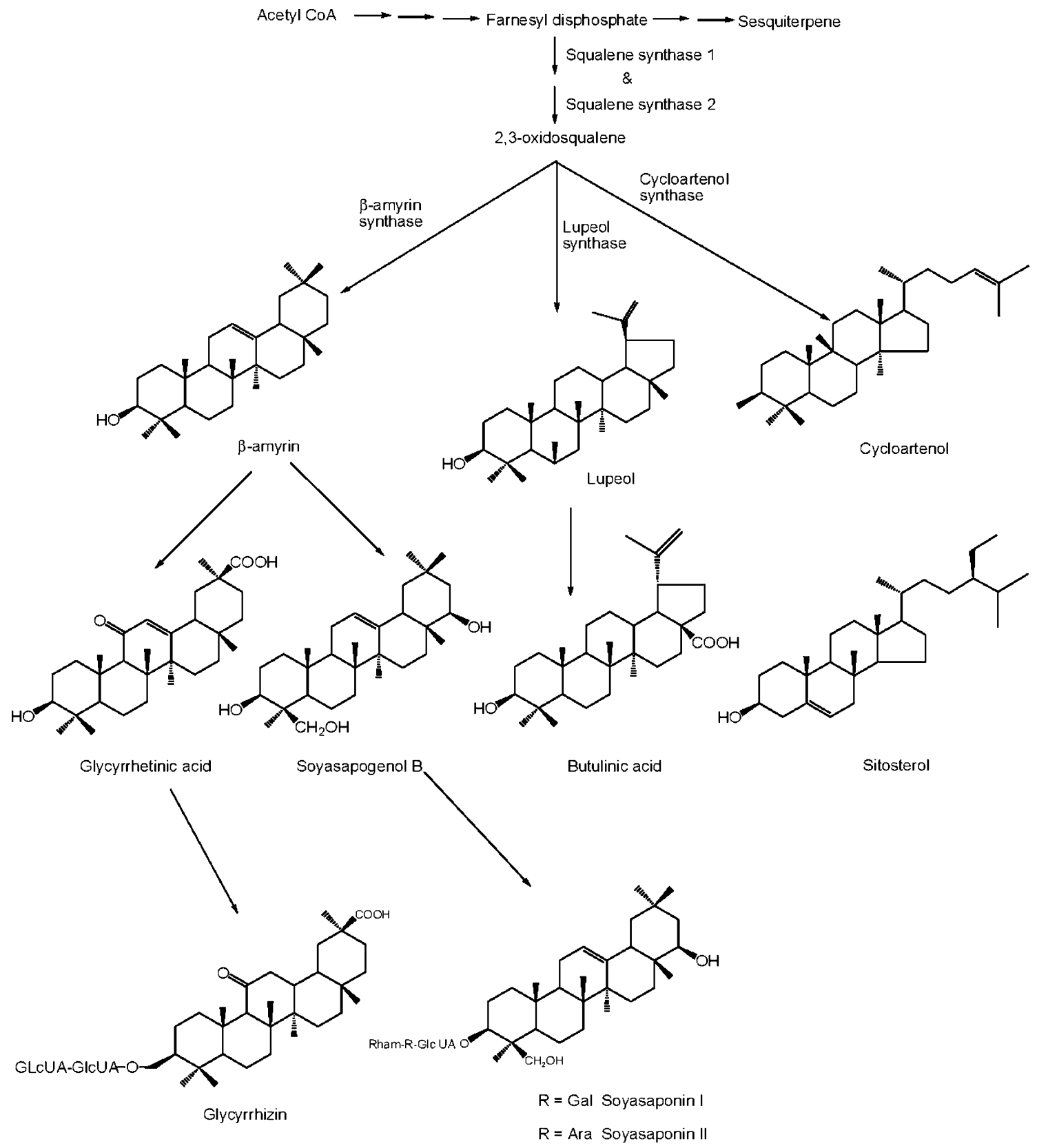

Fig. 4 Biosynthetic pathways of glycyrrhizin in Glycyrrhiza glabra

phase I clinical trial of orally administered D-limonene, 17 women and 15 men aged 35 to 78 with advanced metastatic solid tumors received an average of three treatment cycles of 21 days at dose ranging from 0.5 to $12.0 \mathrm{~g} / \mathrm{m}^{2}$ body surface area. D-Limonene was slowly absorbed, the maximal plasma concentration being attained at 1-6 h. The mean peak plasma concentrations of D-limonene were 11-20 $\mu \mathrm{mol} / \mathrm{L}$ and the predominant metabolites were perillic acid $(21-71 \mu \mathrm{mol} / \mathrm{L})$, dihydroperillic acid $(17-28 \mu \mathrm{mol} / \mathrm{L})$ and isomers of perillic acid. After reaching these peaks, the plasma concentration decreased according to first-order kinetics (Vigushin et al. 1998;
Saldanha and Tollefsbol 2012). Carcinomas regress when D-limonene is added to the diet either when the tumour is small or still capable of spontaneously regressing. D-Limonene appears to act in cytostatic fashion. It is predicted that D-limonene inhibits the isoprenylation of small $\mathrm{G}$ proteins (Hogg et al. 1992; Gould et al. 1994; Miller et al. 2011).

\section{1,8 -Cineole}

In humans, 1,8-cineole inhibits sensory irritations caused by octanol and methanol with sensitive volunteers. Both 
methanol and octanol are well-known chemicals causing skin irritation. The result that 1,8-cineole, whose ability to activate TRMP8 is lower than methanol, inhibited methanol-evoked skin irritation clearly suggests that inhibitory effects of 1,8-cineole are probably due to inhibition of TRPA1, but not activation of TRMP8 (Takashi et al. 2012; Bastos et al. 2011). 1,8-cineole not only reduces exacerbation rate but also provides clinical benefits as manifested by improved airflow obstruction, reduced severity of dyspnea and improvement of health status (Juergens et al. 1998, 2003). Therefore, it can provide a useful treatment option for symptomatic patients with COPD in addition to treatment according to the guidelines. The results have to be seen in context with socio-economic aspects. As COPD is an extremely costly disease and cause of major financial and social burden concomitant therapy with 1,8-cineole can be recommended. These finding correspond to the interpretation of the efficacy study with carbocysteine but not with acetylcysteine because this medication did not show a significant reduction of exacerbations (Zhang et al. 2008; Decramer et al. 2005; Worth et al. 2009).

\section{Boswellic acid}

More recently extracts of resin enriched in pentacyclic triterpenoid known as boswellic acid have been employed as anti-inflammatory drugs (Anthoni et al. 2006). Pilot clinical studies do indeed suggest that boswellic acid promotes pain control and dampens inflammation in osteoarthritis and colitis and helps to control the brain oedema associated with radiotherapy of cerebral tumours; anti-inflammatory effects of rodent models have also been demonstrated (Gupta et al. 2001; Kimmatkar et al. 2003). Initial attempts to clarify the molecular target of boswellic acid in inflammatory disorders determined that keto-boswellic acid can inhibit 5-lipoxygenase in low molecular concentrations (Bhushan et al. 2007). This suggested that boswellic acid preparation might dampen inflammation by blocking leukotriene synthesis (Joos et al. 2006). In vitro studies reveals boswellic acid in a dosedependent manner blocks the synthesis of pro-inflammatory 5-lipoxygenase product including 5-hydroxyeicosatetraenoic acid and leukotriene B4, which cause bronchoconstriction chemotaxis and increase vascular permeability (Shao et al. 1998). Boswellic acid from Boswellia serrata also have inhibitory and apoptotic effect against the cellular growth of leukemia HL-60 cells (Huang et al. 2000). Clinical trials have demonstrated promising benefits from boswellic acids in rheumatoid arthritis, chronic colitis, ulcerative colitis, Crohn's disease and bronchial asthma in addition to benefits for brain tumour patients. The effects of boswellic acid on central signaling pathways in human platelets and on various platelet functions have been investigated. It also caused a pronounced mobilization of $\mathrm{Ca}^{2+}$ from internal stores and induced the phosphorylation of p38 MAPK and elicits functional platelet responses (Poeckel et al. 2005). Boswellic acids have also been observed to inhibit human leukotriene elastase which may be involved in pathogenesis of emphysema. Human leukotriene elastase also stimulates mucus secretion and thus may play a role in cystic fibrosis, chronic bronchitis and acute respiratory distress syndrome (Rall et al. 1996; Safayhi et al. 1997). However, the clinical trials of gum-resin of Boswellia serrata have shown to improve symptoms in patients with osteoarthritis and rheumatoid arthritis (Poeckel and Werz 2006; Poeckel et al. 2006).

\section{Betulinic acid}

Betulinic acid is a naturally occurring pentacyclic triterpene that exhibits a variety of biological activities including potent antiviral and anticancer effects (Alakurtti et al. 2006; Hsu et al. 2012). Mitochondria from cells, which were treated with betulinic acid, induced the cleavage of both caspase- 3 and caspase- 8 in cytosolic extracts. Cleavage of caspase- 3 and 8 was preceded by disturbance of mitochondrial membrane potential and by generation of reactive oxygen species. Activation of caspase cascade was required for betulinic acid-triggered apoptosis. Interestingly, neuroblastoma cells resistant to doxorubicin-mediated apoptosis were still responsive to treatment with betulinic acid (Fulda et al. 1998; Fulda 2008). This revealed that betulinic acid inhibits the catalytic activity of topoisomerase I (Choudhary et al. 2002). Furthermore, betulinic acid exerts context dependent effects on cell cycle, it also reduces the expression of p21 protein in glioblastoma cells (Rieber and Strasberg Rieber 1998).

\section{$\beta$-Sitosterol}

It is used to prevent and relieve prostate symptoms and has been tested for thousands of years in Asia and Mediterranean where the incidence of prostate problems-including prostate cancer-is considerably lower than that in the United States and Canada (Wilt et al. 1999; Richelle et al. 2004). Taking $\beta$-sitosterol at the dose of $60-110 \mathrm{mg} /$ day significantly improve urinary symptoms. It increases the maximum urinary flow and decreases the volume of the urine left in the bladder. Like saw palmetto, $\beta$-sitosterol does not affect prostate size (Awad et al. 2000). $\beta$-Sitosterol is also used to lower cholesterol. It is an ingredient in the cholesterol-lowering margarine which is used to be known as take control (Berges et al. 2000). Aging is the main cause of enlarged prostate glands (Glynn et al. 1985). Testosterone is converted into another more powerful male hormone dihydrotestosterone in prostate cells. Dihydrotestosterone is responsible for triggering the division of 
prostate cells so their numbers increase by cell division process. Levels of dihydrotestosterone are known to be five times higher in enlarged prostate glands in those of normal sized prostate. If the conversion of testosterone to dihydrotestosterone is prevented, the BPH may not occur and may even be reversed once it has developed. $\beta$-Sitosterol works for enlarged prostate by inhibiting an enzyme called 5 - $\alpha$-reductase, blocking the conversion of testosterone into dihydrotestosterone, thereby decreasing the amount of dihydrotestosterone. Since, dihydrotestosterone is considered to be responsible for the enlargement of prostate, $\beta$ sitosterol helps to support normal prostate size. $\beta$-Sitosterol has been recommended by physicians for over 20 years as natural supplement to promote prostate health (Bent and Kane 2006). Based on the highly preliminary evidence, it has been suggested that $\beta$-sitosterol may also help strengthen the immune system (Pegel 1997). One study suggests that $\beta$-sitosterol can help prevent the temporary immune weakness that typically occurs during recovery from endurance exercise and can lead to post-race infections (Bouic et al. 1999). A randomized controlled trial of 47 patients with pulmonary tuberculosis investigated adjuvant $\beta$-sitosterol therapy vs placebo (Silveira e Sá et al. 2013). The $\beta$-sitosterol treatment group (average dose $60 \mathrm{mg} /$ day) demonstrated increased weight gain, higher lymphocyte and eosinophil count and a generally faster clinical recovery (Donald et al. 1997).

\section{Ursolic acid}

Mice fed with ursolic acid diet for 8 weeks delayed formation of prostate intraepithelial neoplasia. Similarly, mice fed with ursolic acid for 6 weeks inhibited progression of prostate intraepithelial neoplasia to adenocarcinoma as determined by hematoxylin and eosin staining. With respect to the molecular mechanism, it was observed that ursolic acid down regulated the activation of various proinflammatory mediators including NF- $\kappa \mathrm{B}, \mathrm{TNF}-\alpha$ and IL-6 (Shanmugum et al. 2012).

\section{Future prospects}

The terpenoids are synthesized from two five-carbon building blocks, which are known as isoprenoid units. Based on the number of building blocks, terpenoids are grouped into several classes, such as monoterpenes (e.g. carvone, geraniol, D-limonene and peril alcohol), diterpenes (e.g. retinol and retinoic acid), triterpenes (e.g. betulinic acid, lupeol, oleanolic acid and ursolic acid) and tetraterpenes (e.g. $\alpha$-carotene, $\beta$-carotene, lutein, and lycopene) (Thoppil and Bishayee 2011; Rabi and Bishayee 2009a; Withers and Keasling 2007). Terpenoids have been found to be useful for the treatment of various types of diseases and disorders viz, antimicrobial, antifungal, antiparasitic, antiviral, antihyperglycemic, antihypoglycemic, anti-inflammatory and immunomodulatory properties (Wagner and Elmadfa 2003; Shah et al. 2009; Sultana and Ata 2008).

The development of transgenic plants against biotic stress like as insects has been a major successful scientific approach, mirrored by practical success of a limited number of pest-resistant transgenic crops in various countries. In some well-developed countries, this has been a result of vocal opposition to plant transformation technology itself; but in many examples, in both developed and developing countries, it is more a case of great potential economic benefits not being sufficient to make the introduction of transformed varieties of crops commercially viable.

The development of zero-cannabinoid cannabis chemotype has provided crude drugs that will facilitate discernment of the pharmacological effects and contributions of different fractions. Breeding work has already resulted in chemotypes that produce $98 \%$ of monoterpenes as myrcene or $77 \%$ as D-limonene. Through selective breeding of high terpenoid and phytocannabinoid-specific chemotype, has thus become rational target that may lead to novel approaches in treatment of different types of diseases and disorders.

The terpenes play important roles in plant interactions, plant defenses and the other environmental stresses (Chen et al. 2011). To better understand the physiological and ecological roles of specific terpene synthase genes and enzymes research in various areas is required. Roles of specific terpenes or general roles of classes of terpene synthases, regulation of terpene synthesis, phylogeny of terpene synthases, must be examined thoroughly in plants and ideally in the natural environments of the plants that produce these terpenes. The terpene synthase gene's manipulation and their expression in model and non-model plants will be critical at this end. Despite many discoveries about the functions of terpene synthase genes, the ongoing and future structural and biochemical investigations of terpene synthases will continue to be field of exciting new discoveries. At present, functional characterization and regulation of terpene synthases have been completed only for subsets of terpene synthase families, including Arabidopsis, grapevine and spruce. Similar to other plant species, the biochemical functions and phylogeny of various number of terpene synthase proteins have already been established and known; there are only few experimentally determined three-dimensional structures of terpene synthases of plant origin (Gennadios et al. 2009; Kampranis et al. 2007). At the same time, large transcriptome sequencing projects targeted at plants species that produce interesting medicinally important metabolites will enhance 
the identification of comprehensive sets of terpene synthase genes in a large variety of non-model systems. An improved and updated knowledge on regulation of terpene metabolism and phylogeny of terpene synthases will facilitate the manipulation of terpene biosynthetic pathways for improvement of agronomic traits, biotransformation of medicinally important terpenes, floral scents (Lücker et al. 2001), plant defense against pests and pathogens (Schnee et al. 2006) and production of known and novel phytocompounds (Bohlmann and Keeling 2008).

Acknowledgments Authors are very much grateful to Professor (Dr.) A. N. Pathak, Director, Institute of Biotechnology, Amity University Rajasthan, for proof reading and moral support in preparing of this review paper.

Conflict of interest Authors hereby declare no conflict of interest.

Open Access This article is distributed under the terms of the Creative Commons Attribution License which permits any use, distribution, and reproduction in any medium, provided the original author(s) and the source are credited.

\section{References}

Abe I, Rohmer M, Prestwich GD (1993) Enzymatic cyclization of squalene and oxidosqualene to sterols and triterpenes. Chem Rev 93:2189-2206

Adam KP, Zapp J (1998) Biosynthesis of the isoprene units of chamomile sesquiterpenes. Phytochemistry 48:953-959

Aharoni A, Giri AP, Deuerlein S, Griepink F, de-Kogel WJ, Verstappen FWA, Verhoeven HA, Jongsma MA, Schwab W, Bouwmeester HJ (2003) Terpenoid metabolism in wild type and transgenic Arabidopsis plants. Plant Cell 15:2866-2884

Ait-Ali T, Swain SM, Reid JB, Sun TP, Kamiya Y (1994) The $L S$ locus of pea encodes the gibberellin biosynthesis enzyme entkaurene synthase A. Plant J 11:443-454

Alakurtti S, Mäkelä T, Koskimies S, Yli-Kauhaluoma J (2006) Pharmacological properties of the ubiquitous natural product betulinic acid. Eur J Pharm Sci 29:1-13

Anthoni C, Laukoetter MG, Rizken E (2006) Mechanism underlying the anti-inflammation actions of boswellic acid derivatives in experimental colitis. Am J Physiol Gastrointest Liver Physiol 290:G1131-G1137

Aoyogi K, Beyou A, Moon K, Fang L, Ulrich T (1993) Isolation and characterization of cDNAs encoding wheat 3-hydroxy-3-methylglutaryl CoA reductase. Plant Physiol 102:623-628

Arimura G, Huber DPW, Bohlmann J (2004a) Forest tent caterpillar (Malacosoma disstria) induce local and systemic diurnal emissions of terpenoid volatiles in hybrid poplar (Populus trichocarpa $\times$ deltoids: cDNA cloning functional characterization and patterns of gene expression of (-)-germacrene D-synthase, PtdTPS1. Plant J 37:603-616

Arimura G, Ozawa R, Kugimiya S, Takabayashi J, Bohlmann J (2004b) Herbivore-induced defence response in a model legume: two spotted spider mites Tetranychus urticae, induce emission of (E)- $\beta$-ocimene synthase in Lotus japonicas. Plant Physiol 135:1976-1983

Ashour M, Wink M, Gershenzon J (2010) Biochemistry of terpenoids: monoterpenes, sesquiterpenes and diterpenes. In: Wink M (ed)
Annual plant reviews: biochemistry of plant secondary metabolism, vol 40, 2nd edn. Wiley, New York

Atsbaha Zebelo S, Bertea CM, Bossi S, Occhipinti A, Gnavi G, Maffei ME (2011) Chrysolina herbacea modulate terpenoid biosynthesis of Mentha aquatica L. PLoS One 6:e17195

Aubourg S, Lecharny A, Bohlmann J (2002) Genomic analysis of the terpenoid synthase gene family of Arabidopsis thaliana. Mol Genet Genomics 267:730-745

Augustin JM, Kuzina V, Andersen SB, Bark S (2011) Molecular activities, biosynthesis and evolution of triterpenoid saponin. Phytochemistry 72:435-457

Awad AB, Chan KC, Downie AC, Fink KC (2000) Peanuts as source of $\beta$-sitosterol, a sterol with anticancer properties. Nutr Cancer $36: 238-241$

Bach TJ (1995) Some aspects of isoprenoid biosynthesis in plants? a review. Lipids 30:191-202

Back K, Chappel J (1996) Identifying functional domains within terpene cyclases using a domain-swapping strategy. Proc Natl Acad Sci USA 93:6841-6845

Baker J, Franklin DB, Parker J (1992) Sequence and characterization of the gcpE gene of Escherichia coli. FEMS Microbiol Lett 73:175-180

Baker CH, Matsuda SPT, Liu DR, Corey EJ (1995) Molecular cloning of the human gene encoding lanosterol synthase from a liver cDNA library. Biochem Biophys Res Commun 213:154-160

Balandrin MF, Klocke JA, Wurtele ES, Bollinger WH (1985) Natural plant chemicals: sources of industrial and medicinal materials. Science 228:1154-1160

Basson ME, Thorsness M, Finer-Moore J, Stroud RM, Rine J (1988) Structural and functional conservation between yeast and human 3-hydroxy-3-methylglutaryl CoA reductase, the rate limiting enzyme of sterol biosynthesis. Mol Cell Biol 8:3797-3808

Bastos VPD, Gomes AS, Lima FJB, Brito JB, Soares PMG, Pinho JPM, Silva CS, Santos AA, Souza MHLP, Magalhâes PJC (2011) Inhaled 1, 8-cineole reduces inflammatory parameters in airways of ovalbumin-challenged guinea pigs. Basic Clin Pharmacol Toxicol 108:34-39

Basyuni M, Oku H, Inafuka M, Baba S, Iwasaki H, Oshiro T, Okabe T, Shibuya M, Ebizuka Y (2006) Molecular cloning and functional expression of a multifunctional triterpene synthase cDNA from a mangrove species Kandelia candel (L.) Druce. Phytochemistry 67:2517-2524

Basyuni M, Oku H, Tsuijimoto E, Kinjo K, Baba S, Takara K (2007) Triterpene synthases from the Okinawan mangrove tribe, Rhizophoraceae. FEBS J 274:5028-5042

Beilen JB, Poirier Y (2007) Establishment of new crops for the production of natural rubber. Trends Biotechnol 25:522-529

Bensen RJ, Gohal GS, Crane VC, Tossberg JT, Schnable PS, Meeley RB, Briggs SP (1995) Cloning and characterization of the maize An1 gene. Plant Cell 7:75-84

Bent S, Kane C (2006) Saw palmetto for benign prostatic hyperplasia. N Engl J Med 354:557-566

Berges RR, Kassen A, Seng T (2000) Treatment of symptomatic benign prostate hyperplasia with $\beta$-sitosterol: an 18 month follow-up. BJU Int 85:842-846

Besser K, Harpel A, Welsby N, Schauvinhold I, Slocombe S, Li Y, Dixon RA, Broun P (2008) Divergent regulation of terpenoid metabolism in the trichomes of wild and cultivated tomato species. Plant Physiol 149:499-514

Bhushan S, Kumar A, Malik F (2007) A triterpenediol from Boswellia serrata induces apoptosis through both the intrinsic and extrinsic apoptotic pathways in human leukemia HL-60 cells. Apoptosis 12:1911-1926

Bick JA, Lange BM (2003) Metabolic crosstalk between cytosolic and plastidial pathways of isoprenoid biosynthesis:

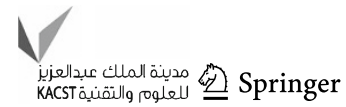


unidirectional transport of intermediates across the chloroplast envelope membrane. Arch Biochem Biophys 415:146-154

Bohlmann J (2012) Pine terpenoid defences in the mountain pine beetle epidemic and in other conifer pest interactions: specialized enemies are eating holes into a diverse, dynamic and durable defence system. Tree Physiol 32:943-945

Bohlmann J, Keeling CI (2008) Terpenoid biomaterials. Plant J 54:656-669

Bohlmann J, Meyer-Gauen G, Croteau R (1998) Plant terpenoid synthases: molecular biology and phylogenetic analysis. Proc Natl Acad Sci USA 95:4126-4133

Bohlmann J, Phillips M, Ramachandiran V, Katoh S, Croteau R (1999) cDNA cloning, characterization and functional expression of four new monoterpene synthase members of the Tpsd gene family from grand fir (Abies grandis). Arch Biochem Biophys 368:232-243

Boughton AJ, Hoover K, Felton GW (2005) Methyl jasmonate application induces increased densities of glandular trichomes on tomato, Lycopersicon esculentum. J Chem Ecol 31:2211-2216

Bouic PJD, Clark A, Lamprecht J (1999) The effects of $\beta$-sitosterol glucoside mixture on selected immune parameters of marathon runners: inhibition of post marathon immune suppression and inflammation. Int J Sports Med 20:258-262

Brendolise C, Yauk YK, Eberhard ED, Wang M, Chagne D, Andre DR, Beuning LL (2011) An unusual plant triterpene synthase with predominant $\alpha$-amyrin producing activity identified by characterizing oxidosqualene cyclases from Malus domestica. FEBS J 278:2485-2499

Burse A, Frick S, Discher S, Tolzin-Banasch K, Kirsch R, Strauß A, Kunert M, Boland W (2009) Always being well prepared for defense: the production of deterrents by juvenile Chrysomelina beetles (Chrysomelidae). Phytochemistry 70:1899-1909

Busquets A, Keim V, Closa M, del Arco A, Boronat A, Arro B, Ferrer A (2008) Arabidopsis thaliana contains single gene encoding squalene synthase. Plant Mol Biol 67:25-36

Calisto BM, Perez-Gil J, Bergua M, Querol-Audi J, Pita I, Imperial S (2007) Biosynthesis of isoprenoids in plants: structure of $2 \mathrm{C}$ methyl-D-erythritol 2,4-cyclodiphosphate synthase from Arabidopsis thaliana. Comparison with bacterial enzymes. Protein Sci 16:2082-2088

Carrie C, Murcha MW, Millar AH, Smith SM, Whelam J (2007) Nine 3-ketoacyl-CoA thiolases (KATs) and acetoacetyl-CoA thiolases (ACATs) encoded by five genes in Arabidopsis thaliana are targeted either to peroxisomes or cytosol but not to mitochondria. Plant Mol Biol 63:97-108

Chen XY, Wang M, Chen Y, Davisson VJ, Heinstein P (1996) Cloning and heterologous expression of a second $(+)$ - $\delta$-cadinene synthase from Gossypium arboreum. J Nat Prod 59:944-951

Chen F, Tholl D, D'Auria JC, Farooq A, Pichersky E, Gershenzon J (2003) Biosynthesis and emission of terpenoid volatiles from Arabidopsis flowers. Plant Cell 15:481-494

Chen F, Tholl D, Bohlmann J, Pichersky E (2011) The family of terpene synthase in plants: a mid size family of genes for specialized metabolism that is highly diversified throughout the kingdom. Plant J 66:212-229

Cheniclet C, Rafia F, Salnt-Guily A, Verna A, Cadre JR (1992) Localization of the enzyme geranyl geranyl pyrophosphate synthase in Capsicum fruits by immunogold cytochemistry after conventional chemical fixation or quick freezing followed by freeze substitution: labeling evolution during fruit ripening. Biol Cell 75:145-154

Choudhary AR, Mandal S, Mitra B, Sharma S, Mukhopadhyay S, Majumdar HK (2002) Betulinic acid, a potent inhibitor of eukaryotic topoisomerase I: identification of the inhibitory step, the major functional group responsible and development of more potent derivatives. Med Sci Monit 8:BR254-BR265
Creelman RA, Mullet JE (1997) Biosynthesis and action of jasmonates in plants. Annu Rev Plant Physiol Plant Mol Biol 48:355-381

Croteau R, Ketchum RE, Long RM, Kaspera R, Wildung MR (2006) Taxol biosynthesis and molecular genetics. Phytochem Rev 5:75-97

Cseke L, Dudareva J, Pichersky E (1998) Structure and evolution of linalool synthase. Mol Biol Evol 15:1491-1498

Cunillera N, Boronat A, Ferrer A (1997) The Arabidopsis thaliana FPS1 gene generates a novel mRNA that encodes a mitochondrial farnesyl diphosphate synthase isoform. J Biol Chem 272:15381-15388

Cunningham FX, Lafend TP, Gannt E (2000) Evidence of a role for LytB in the non-mevalonate pathway of isoprenoid biosynthesis. J Bacteriol 182:5841-5848

Decendit A, Liu D, Ouelhazi L, Doireau P, Mérillon J, Rideau M (1992) Cytokinin-enhanced accumulation of indole alkaloids in Catharanthus roseus cell cultures: the factor affecting the cytokinin response. Plant Cell Rep 11:400-403

Decramer M, Rutten-van Mölken M, Dekhuijzen PN, Trooster T, van Herwaarden C, Pellegrino R, van Schayck CP, Olivieri D, Del Donno M, De Backer W, Lankhorst I, Ardia A (2005) Effects of $\mathrm{N}$-acetylcysteine on outcomes in chronic obstructive disease: a randomized placebo-controlled trial. Lancet 365:1552-1560

Dedryver CA, Lee Ralee A, Fabre F (2010) The conflicting relationships between aphids and men: a review of aphid damage and control strategies. C R Biol 333:539-553

Degenhardt J, Kollner TG, Gershenzon J (2009) Monoterpene and sesquiterpene synthases and the origin of terpene skeletal diversity in plants. Phytochemistry 70:1621-1637

De-Geyter N, Gholami A, Goormachtig S, Goosens A (2012) Transcriptional machineries in jasmonate-elicited plant secondary metabolism. Trends Plant Sci 17:349-359

Dhe-Paganon S, Magrath J, Abeles RH (1994) Mechanism of mevalonate pyrophosphate decarboxylase: evidence for a carbocationic transition state. Biochemistry 33:13355-13362

Doblas VG, Amorim-Silva V, Pose D, Rosado A, Esteban A, Arro M, Azevedo H, Bombarley A, Borsani O, Valpuesta V (2013) The SUD1 gene encodes a putative E3 ubiquitin ligase and is a positive regulation of 3-hydroxy-3-glutaryl CoA reductase activity in Arabidopsis. Plant Cell 25:728-743

Donald PR, Lamprecht JH, Freestone M (1997) A randomized placebo-controlled trial of the efficacy of $\beta$-sitosterol and its glucoside as adjuvants in the treatment of pulmonary tuberculosis. Int J Tuberc Lung Dis 1:518-522

Dornelas MC, Mazzafera P (2007) A genomic approach to characterization of the Citrus terpene synthase gene family. Genet Mol Biol 30:832-840

Drew DP, Dueholm B, Weitzel C, Zhang Y, Sensen CW, Simonsen HT (2013) Transcriptome analysis of Thapsia laciniata Rouy provides insights into terpenoid biosynthesis and diversity in Apiaceae. Int J Mol Sci 14:9080-9098

Ducreux LJM, Morris WL, Prosser IM, Morris JA, Beale MH, Wright F, Shepherd T, Bryan JM, Hedley PE, Taylor MA (2008) Expression profiling of potato germplasm differentiated in quality traits leads to the identification of candidate flavor and texture genes. J Exp Bot 59:4219-4231

Dudareva J, Cseke L, Blanc VM, Pichersky E (1996) Evolution of floral scent in Clarkia: novel patterns of S-linalool synthase gene expression in the $C$. breweri flower. Plant Cell 8:1137-1148

Dudareva N, Martin D, Kish CM, Kolosova N, Gorenstein N, Fäldt J, Miller B, Bohlmann J (2003) (E)- $\beta$-ocimene and myrcene synthase genes of floral scent biosynthesis in snapdragon: function and expression of three terpene synthase genes of a new terpene synthase sub-family. Plant Cell 15:1227-1241 
Dudareva N, Negre F, Nagegowda DA, Orlova I (2006) Plant volatiles: recent advances and future perspectives. Crit Rev Plant Sci 25:417-440

Elson CE, Maltzman TH, Boston JL (1988) Anticarcinogenic activity of D-limonene during the initiation and promotion/progression stage of DMBA-induced rat mammary carcinogenesis. Carcinogenesis 9:331-332

El-Wakeil NE, Wolkmar C, Sallam AA (2010) Jasmonic acid induces resistance to economically important insect pests in winter wheat. Pest Manag Sci 66:549-554

Facchini PJ, Chappel J (1992) Gene family for an elicitor induced sesquiterpene cyclase in tobacco. Proc Natl Acad Sci USA 89:11088-11092

Falara V, Akhtar TA, Nguyen TT, Spyropoulou EA, Blecker PM, Schauvinhold I, Matsuba Y, Bonini ME, Schimiller AL, Last RL, Schuurink RC, Richersky E (2011) The tomato terpene synthase gene family. Plant Physiol 157:770-789

Fäldt J, Martin D, Miller B, Rawat S, Bohlmann J (2003) Traumatic resin defence in Norway spruce (Picea abies): methyl jasmonate-induced terpene synthase gene expression and cDNA cloning and functional characterization of (+)-3-carene synthase. Plant Mol Biol 51:119-133

Field B, Osbourn AE (2008) Metabolic diversification-independent assembly of operon like gene clusters in different plants. Science 320:543-547

Fulda S (2008) Betulinic acid for cancer treatment and prevention. Int J Mol Sci 9:1096-1107

Fulda S, Susin SA, Kroemer G, Debatin KM (1998) Molecular ordering of apoptosis induced by anticancer drugs in neuroblastoma cells. Cancer Res 58:4453-4460

Gantet P, Imbault N, Thiersault M, Doireau P (1998) Necessity of a functional octadecanoic pathway for indole synthesis by Catharanthus roseus cell suspension cultured in an auxin-starved medium. Plant Cell Physiol 39:220-225

Gaut BS (2002) Evolutionary dynamics of grass genomes. New Phytol 154:15-28

Gennadios HA, Gonzalez V, Di Costanzo L, Li A, Yu F, Miller DJ, Allemann RK, Christianson DW (2009) Crystal structure of (+)$\delta$-cadinene synthase from Gossypium arboreum and evolutionary divergence of metal binding motifs for catalysis. Biochemistry 48:6175-6183

Gershenzon J, Kreish W (1999) Biochemistry of terpenoids: monoterpenes, sesquiterpenes, diterpenes, sterols, cardiac glycosides and steroid saponins. In: Wink $M$ (ed) Biochemistry of plant secondary metabolism. CRC Press, Florida, pp 222-299

Ginger ML, McFadden GI, Michels PAM (2010) Rewiring and regulation of cross-compartmentalized metabolism in protists. Phil Trans R Soc Biol 365:831-845

Glas JJ, Schimmel BCJ, Alba JM, Escobar-Bravo R, Schuurink RC, Kant MR (2012) Plant glandular trichomes as targets for breeding or engineering of resistance to herbivores. Intl J Mol Sci 13:17077-17103

Glynn RJ, Campion EW, Bouchard GR, Silbert JE (1985) The development of benign of prostatic hyperplasia among volunteers in the normative aging study. Am J Epidemiol 121:78-90

Gould MN, Moore CJ, Zhang R, Wang B, Kennan WS, Hagg JD (1994) Limonene chemoprevention of mammary carcinoma induction following direct in situ transfer of $v$-Ha-ras. Cancer Res 54(3540):3543

Grauvogel C, Peterson J (2007) Isoprenoid biosynthesis authenticates the classification of the green alga Mesostigma viride as an ancient streptophyte. Gene 396:125-133

Gray DW, Breneman SR, Topper LA, Sharkey ID (2011) Biochemical characterization and homology modeling of methyl butenol synthase and implication for understanding hemiterpene synthase evolution in plants. J Biol Chem 286:20582-20590
Guhling O, Hobl B, Yeast T, Jetter R (2006) Cloning and characterization of lupeol synthase involved in the synthesis of epicuticular wax crystals on stem and hypocotyl surfaces of Ricinus communis. Arch Biochem Biophys 448:60-72

Gupta I, Parihar A, Malhotra P (2001) Effects of gum-resin of Boswellia serrata in patients with chronic colitis. Planta Med 67:391-395

Han JY, Kwon YS, Yang DC, Jung YR, Choi YE (2006) Expression and RNA interference-induced silencing of the dammarenediol synthase gene in Panax ginseng. Plant Physiol 47:1653-1662

Han JY, In JG, Kwon YS, Choi YE (2010) Regulation of ginsenoside and phytosterol biosynthesis by RNA interferences of squalene epoxide gene in Panax ginseng. Phytochemistry 71:36-46

Haralampidis K, Bryan G, Qi X, Papadopoulou K, Bakht S, Melton R, Osbourn A (2001) A new class of oxidosqualene cyclases directs synthesis of antimicrobial phytoprotectants in monocots. Proc Natl Acad Sci USA 98:13431-13436

Haralampidis K, Trojanowska M, Osbourn AE (2002) Biosynthesis of triterpenoid saponins in plants. Adv Biochem Eng Biotechnol 75:31-49

Hare JD, Walling LL (2006) Constitutive and jasmonate-inducible traits of Datura wrightii. J Chem Ecol 32:29-47

Hayashi H, Hiraoka N, Ikeshiro Y, Kushiro T, Morita M, Shibuya M, Ebizuka Y (2000) Molecular cloning and characterization of cDNA for Glycyrrhiza glabra cycloartenol synthase. Biol Pharm Bull 23:231-234

Hayashi H, Huang PY, Kirakosyan A, Inoue K, Hiraoka N, Ikeshiro Y, Kushiro T, Shibuya M, Ebizuka Y (2001) Cloning and characterization of a cDNA encoding $\beta$-amyrin synthase involved in glycyrrhizin and soyasaponin biosynthesis in licorice. Biol Pharm Bull 24:912-916

Hayashi H, Huang P, Inou K (2003) Up-regulation of soyasaponin biosynthesis by methyl jasmonate in cultured cells of Glycyrrhiza glabra. Plant Cell Physiol 44:404-411

Hayashi H, Hung P, Takada S, Obinata M, Inoue K, Shibuya M, Ebizuka Y (2004) Differential expression of three oxidosqualene cyclase mRNAs in Glycyrrhiza glabra. Biol Pharm Bull 27:1086-1092

Hayashi K, Kawaide H, Notomi M, Sakigi Y, Matsuo A, Nozaki H (2006) Identification and functional analysis of bifunctional entkaurene synthase from the moss Physcomitrella patens. FEBS Lett 580:6175-6181

Hedhili S, Courdavault V, Giglioli-Guivarc'h N, Gantet P (2007) Regulation of terpene moiety biosynthesis of Catharanthus roseus terpene indole alkaloids. Phytochem Rev 6:341-351

Hemmerlin A, Hoeffler JF, Meyer O, Tritsch D, Kagan IA, Grosdemange-Billiard C, Rohmer M, Bach TJ (2003) Cross talk between the cytosolic mevalonate and the plastidial methylerythritol phosphate pathways in tobacco bright yellow-2 cells. J Biol Chem 278:26666-26676

Herrera LP, Casas CE, Bates ML, Guest JD (2005) Ultrastructural study of the primary olfactory pathway in Macaca fascicularis. J Comp Neurol 488:427-441

Herz S, Wungsintaweekul J, Schulir CA, Hecht S, Luttgen H, Sagner S, Fellermeier M, Eisenreich W, Zenk MH, Bacher A, Rohdich F (2000) Biosynthesis of terpenoids: YgbB protein converts 4-diphosphocytidyl-2C-methyl-D-erythritol 2,4-cyclodiphosphate. Proc Natl Acad Sci USA 97:2486-2490

Hiltpold I, Turlings TCJ (2008) Below ground chemical signaling in maize: when simplicity rhymes with efficiency. J Chem Ecol 34:628-635

Hogg JD, Lindstorm MJ, Gould MN (1992) Limonene-induced regression of mammary carcinomas. Cancer Res 52:4021-4026

Hseih MH, Chang CY, Hsu SJ, Chen JJ (2008) Chloroplast localization of mitochondrial genes of methylerythritol-4phosphate pathway enzymes and regulation of mitochondrial

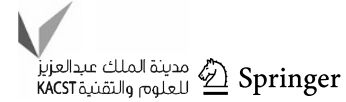


genes in ispE albino mutants in Arabidopsis. Plant Mol Biol 66:663-673

Hsu TI, Wang MC, Chen SY, Huang ST, Yeh YM, Su WC, Chang WC, Hung JJ (2012) Betulinic acid decreases specificity protein 1 (sp1) level via increasing the sumoylation of sp1 to inhibit lung cancer growth. Mol Pharmacol 82:1115-1128

Huang MT, Badmaev V, Ding Y (2000) Antitumor and anticarcinogenic activities of triterpenoid $\beta$-boswellic acid. Biofactors 13:225-230

Huang M, Abel C, Sohrabi R, Petri J, Haupt I, Cosmano J, Gershenzon J, Tholl D (2010) Variation of herbivore-induced volatile terpene among Arabidopsis ecotypes depends on allelic differences and subcellular targeting of two terpene synthases TPS02 and TPS03. Plant Physiol 153:1293-1310

Hudgins JW, Franceschi VR (2004) Methyl jasmonate-induced ethylene production is responsible for conifer phloem defense responses and reprogramming of stem cambial zone for traumatic resin duct formation. Plant Physiol 135:2134-2149

Hwang BK, Sung NK (1989) Effect of metalaxyl on capsidiol production in stems of pepper plants infected with Phytophthora capsici. Plant Dis 73:748-751

Igimi H, Tamura R, Toraishi K (1991) Medical dissolution of gallstones, clinical experience of D-limonene as a sample, safe and effective solvent. Dig Dis Sci 36:200-208

Igual JC, Gonzalez-Bosch C, Dopazo J, Perez-Ortin JE (1992) Phylogenetic analysis of thiolase family: implications for the evolutionary origin of peroxisomes. J Mol Evol 35:147-155

Iijima Y, Davidovich-Rikanati R, Fridman E, Garg DR, Bark K, Lewinsohn E, Pichersky E (2004) The biochemical and molecular basis for the divergent patterns in the biosynthesis of terpenes and phenyl propenes in the peltate glands of the three cultivars of basil. Plant Physiol 136:3724-3736

Irmisch S, Krause ST, Kunert G, Gershenzon J, Degenhardt J, Kollner TG (2012) The organ specific expression of terpene synthase genes contributes to the terpene hydrocarbon composition of chamomile essential oils. BMC Plant Biol 12:84

Isaacson T, Kosma DK, Matas AJ, Buda GJ, He Y, Yu B, Pravitasari A, Batteas JD, Stark RE, Jenks ME, Rose JKC (2009) Cutin deficiency in the tomato fruit cuticle consistently affects resistance to microbial infection and biomechanical properties, but not transpirational water loss. Plant J 60:363-377

Iturbe-Ormaetxe I, Haralampidis K, Papadopoulou K, Osbourn AE (2003) Molecular cloning and characterization of triterpene synthases from Medicago truncatula and Lotus japonicus. Plant Mol Biol 51:731-743

Jaio YN, Wickett NJ, Ayyampalayam S, Chanderbali AS, Landherr L, Ralph PE, Tonisho LP, Hu Y, Liang HY, Soltis PS (2011) Ancestral polyploidy in seed plants and angiosperms. Nature 473:97-100

Jenner H, Townsend B, Osbourn A (2005) Unravelling triterpene glycoside synthesis in plants: phytochemistry and functional genomics join forces. Planta 220:503-506

Jia X, Xia D, Louzada ES (2005) Molecular cloning and expression analysis of a putative terpene synthase gene from Citrus. J Am Soc Hortic Sci 130:454-458

Joos SS, Rosemann T, Szecsenyi J, Hahn EG, Willich SN, Brinkhaus B (2006) Use of complementary and alternative medicine in Germany-a survey of patients with inflammatory bowel disease. BMC Complement Altern Med 6:19

Juergens UR, Stober M, Vetter H (1998) Steroid like inhibition of monocyte arachidonic acid metabolism and IL-1 $\beta$ production by 1,8-cineole. Atemwegs Lungenkrankneitan 24:3-11

Juergens UR, Dethlefsen U, Steinkamp G, Gillisena RR, Vetter H(2003) Anti-inflammatory activity of 1,8-cineole in bronchial asthma: a double-blind placebo-controlled trial. Respir Med 97:250-256

Kai G, Zho AL, Zhang L, Li Z, Guo B, Zhang D (2006) Characterization and expression profile analysis of a new cDNA encoding taxadiene synthase from Taxus media. J Biochem Mol Biol 38:668-675

Kajikawa M, Yamato KT, Fukuzawa H, Sakai Y, Uchida H, Ohyama $\mathrm{K}$ (2005) Cloning and characterization of a cDNA encoding $\beta$ amyrin synthase from petroleum plant Euphorbia tirucalli L. Phytochemistry 66:1759-1766

Kampranis SC, Loannidis D, Purvis A, Mahrez W, Ninga E, Katerelos NA, Anssour S, Dunwell JM, Degenhardt J, Makris AM, Goodenough PW, Johnson CB (2007) Rational conversion of substrate and product specificity in a Salvia monoterpene synthase: structural insights into the evolution of terpene synthase function. Plant Cell 19:1994-2005

Kappers IF, Aharoni A, van Harpen TWJM, Luckerhoff LLP, Dick M, Bouwmeester HJ (2005) Genetic engineering of terpenoid metabolism attracts bodyguards to Arabidopsis. Science 309:2070-2072

Kawano N, Ichinose K, Ebizuka Y (2002) Molecular cloning and functional expression of cDNAs encoding oxidosqualene cyclases from Costus speciosus. Biol Pharm Bull 27:1086-1092

Kawoosa T, Singh H, Kumar A, Sharma SK, Devi K, Dutt S, Vats SK, Sharma M, Ahuja PS, Kumar S (2010) Light and temperature regulated terpene biosynthesis: hepatoprotective monoterpene picroside accumulation in Picrorhiza kurrooa. Funct Integr Genomics 10:393-404

Keeling CI, Weisshar S, Lin RP, Bohlmann J (2008) Functional plasticity of paralogous diterpene synthases involved in conifer defense. Proc Natl Acad Sci USA 105:1085-1090

Keeling CI, Dullat HK, Ralph SG, Jancsik S, Bohlmann J (2010) Identification and function characterization of monofunctional ent-copalyl diphosphate and ent-kaurene synthases in white spruce (Picea glauca) reveal different patterns for diterpene synthase evolution for primary and secondary metabolism in gymnosperms. Plant Physiol 152:1197-1208

Keeling CI, Weisshaar S, Ralph SG, Jancsik S, Hamberger B, Dullat HK, Bohlmann J (2011) Transcriptome mining, functional characterization and phylogeny of a large terpene synthase family in spruce (Picea spp.). BMC Plant Biol 11:43

Ketchum RE, Gibson DM, Croteau RB, Shuler ML (1999) The kinetics of taxoid accumulation in cell suspension cultures of Taxus following elicitation with methyl jasmonate. Biotechnol Bioeng 62:97-105

Kim OT, Bang KH, Jung SJ, Kim YC, Kim SH, Hyun DY, Cha SW (2010) Molecular characterization of ginseng farnesyl diphosphate synthase gene and its up-regulation by methyl jasmonate. Biol Planta 54:47-53

Kimmatkar N, Thawani V, Hingorani L (2003) Efficacy and tolerability of Boswellia serrata extract in treatment of osteoarthritis of knee- a randomized double-blind placebo controlled trial. Phytomedicine 10:3-7

Kirby J, Romanini DW, Paradise EM, Keasling JD (2008) Engineering triterpene production in Saccharomyces cerevisiae- $\beta$-amyrin synthase from Artemisia annиa. FEBS J 275:1852-1859

Kodama R, Yano T, Furukawa K, Noda K, Ide H (1976) Studies on the metabolism of D-limonene. IV. Isolation and characterization of new metabolites and species differences in metabolism. Xenobiotica 6:377-389

Kolesnikova MD, Xiong QB, Lodeiro S, Hua L, Matsuda SPT (2006) Lanosterol biosynthesis in plants. Arch Biochem Biophys 447:87-95

Kölner TG, Schnee C, Gershenzon J, Degenhardt J (2004) The variability of sesquiterpenes from two Zea mays cultivars is controlled by allelic variations of two terpene synthase genes encoding stereoselective multiple product enzymes. Plant Cell 16:1115-1131

Korth KL, Jaggard DAW, Dixon RA (2000) Developmental and light regulated post-translational control of 3-hydroxy-3-methylglutaryl CoA reductase level in potato. Plant $\mathrm{J}$ 23:507-516 
Krishnan NM, Pattnaik S, Jain P, Gaur P, Chaudhary R, Vaidyanathan S, Deepak S, Hariharan AK, Bharathkrishna PG, Nair J, Varghese L, Valivarthi NK, Dhas K, Ramaswami K, Panda B (2012) A draft of the genome and four transcriptomes of a medicinal and pesticidal angiosperm Azadirachta indica. BMC Genomics 13:464

Krokene P, Nagy NE, Krekling T (2008) Traumatic resin duct and polyphenolic parenchyma cells in conifers. In: Schaller A (ed) Induced plant resistance to herbivory. Springer, Dordrecht, pp 147-169

Kushiro T, Shibuya M, Ebizuka Y (1998) $\beta$-Amyrin synthase: cloning of oxidosqualene cyclase that catalyses the formation of the most popular triterpene among higher plants. Eur J Biochem 256:238-244

Kuzuyama T (2002) Mevalonate and non-mevalonate pathways for isoprene units. Biosci Biotechnol Biochem 66:1619-1627

Lange BM, Ahkami A (2013) Metabolic engineering of plant monoterpene, sesquiterpene and diterpenes-current status and future opportunities. Plant Biotechnol J 11:169-196

Lange BM, Turner GW (2013) Terpenoid biosynthesis in glandular trichomes-current status and future opportunities. Plant Biotechnol J 11:2-22

Lange BM, Severin K, Bechthold A, Heide L (1998) Regulatory role of microsomal 3-hydroxy-3-methylglutaryl CoA reductase for shikonin biosynthesis in Lithospermum erythrorhizon cell suspension cultures. Planta 204:234-241

Laule O, Füholz A, Chang H-S, Zhu T, Wang X, Heifetz PB, Gruissem W, Lange BM (2003) Crosstalk between cytosolic and plastidial pathways of isoprenoid biosynthesis in Arabidopsis thaliana. Proc Natl Acad Sci USA 100:6866-6871

Learned RM, Connolly EL (1997) Light modulates the spatial patterns of 3-hydroxy-3-methylglutaryl CoA reductase gene expression in Arabidopsis thaliana. Plant J 11:499-511

Lee S, Chappel J (2008) Biochemical and genomic characterization of terpene synthases in Magnolia grandiflora. Plant Physiol 147:1017-1033

Leivar P, Gonzalez VM, Castel S, Trelease RN, Lopez-Iglesias C, Arro M, Boronat A, Campos N, Ferrer A, Fernandez-Busquets X (2005) Sub-cellular localization of Arabidopsis 3-hydroxy-3methylglutaryl CoA reductase. Plant Physiol 137:57-69

Leivar P, Antolin-Llovera M, Ferroro S, Closa M, Arro M, Ferrer A, Boronat A, Campos N (2011) Multilevel control of Arabidopsis 3-hydroxy-3-methylglutaryl CoA reductase by protein phosphatase 2A. Plant Cell 23:1494-1511

Lesburg CA, Zhai G, Cane DE, Christianson DW (1997) Crystal structure of pentalenene synthase: mechanistic insights on terpenoid cyclization reactions in biology. Science 277:1820-1824

Lescot M, Piffnelli P, Ciampi AY, Ruiz M, Blanc G, Mack JL, Silva FR, Santos CMR, Hont AD, Garsmeur O (2008) Insights into the Musa genome: syntenic relationships to rice and between Musa species. BMC Genomics 9:58

Li Z, Wang X, Chen F, Kim H-J (2007) Chemical changes and overexpressed genes in sweet in weet basil (Ocimum basilicum L.) upon methyl jasmonate treatment. J Agric Food Chem 55:706-713

Liao Z-H, Chen M, Gong Y-F, Miao Z-Q, Sun X-F, Tang K-X (2006) Isoprenoid biosynthesis in plants: pathway, genes, regulation and metabolic engineering. J Biol Sci 6:209-219

Lluch MA, Masferrer A, Arró M, Boranat A, Ferrer A (2000) Molecular cloning and expression analysis of the mevalonate kinase gene from Arabidopsis thaliana. Plant Mol Biol 42:365-376

Lodeiro S, Xiong Q, Wilson WK, Kolesnikova MD, Onak CS, Matsuda SPT (2007) An oxidosqualene cyclase makes numerous products by diverse mechanisms: a challenge to prevailing concepts of triterpene biosynthesis. J Am Chem Soc 129:11213-11222
Lu S, Xu R, Jia JW, Pang J, Matsuda SPT, Chen XY (2002) Cloning and functional characterization of a $\beta$-pinene synthase from Artemisia аппиа that shows a circadian pattern of expression. Plant Physiol 130:477-486

Lücker J, Bouwmeester HJ, Schwab W, Blass J, van der Plas LH, Verhoeven HA (2001) Expression of Clarkia S-linalool synthase in transgenic Petunia plants results in accumulation of $S$-linalyl$\beta$-D-glucopyranoside. Plant J 27:315-324

Lücker J, Bowen P, Bohlmann J (2004) Vitis vinifera terpenoid cyclases: functional identification of two sesquiterpene synthase cDNAs encoding (+)-valencene synthase and (-)-germacrene D synthase and expression of mono and sesquiterpene synthases in grapevine flowers and berries. Phytochemistry 65:2649-2659

Luskey KL, Stevens B (1985) Human 3-hydroxy-3-methylglutaryl CoA reductase, conserved domains responsible for catalytic activity and sterol regulated degradation. J Biol Chem 260:10271-10277

Mangus S, Bonfill M, Osuna L, Moyano E, Tortoriello J, Cusido RM, Pinot MT, Palazom J (2006) The effect of methyl jasmonate on triterpene and sterol metabolism of Centella asiatica, Ruscus aculeatus and Galphimia glauca cultured plants. Phytochemistry 67:2041-2049

Martin D, Tholl D, Gershenzon J, Bohlmann J (2002) Methyl jasmonate induces traumatic resin ducts, terpenoid resin biosynthesis and terpenoid accumulation in developing xylem of Norway spruce stems. Plant Physiol 129:1003-1018

Martin JJ, Pitera DJ, Withers ST, Newmann JD, Keasling JD (2003) Engineering a mevalonate pathway in Escherichia coli for production of terpenoids. Nat Biotechnol 21:796-802

Martin D, Fäldt J, Bohlmann J (2004) Functional characterization of nine Norway spruce terpene synthase genes and evolution of gymnosperm terpene synthases of the TPS-d sub-family. Plant Physiol 135:1908-1927

Martin DM, Aubourg S, Schouwey MB, Daviet L, Schalk M, Toub O, Lund ST, Bohlmann J (2010) Functional annotation, genomic organization and phylogeny of the grapevine terpene synthase gene family based on genome assembly, FLcDNA cloning and enzyme assay. BMC Plant Biol 10:226

Matarese F, Scalabrelli G, D'Onofrio C (2013) Analysis of the expression of terpene synthase genes in relation to aroma content in two aromatic Vitis vinifera varieties. Funct Plant Biol 40:552-565

Mau CJD, West CA (1994) Cloning of casbene synthase cDNA: evidence for conserved structural features among terpenoid cyclases in plants. Proc Natl Acad Sci USA 91:8497-8501

Mehjerdi MZ, Bihamata M-R, Omidi M, Naghavi M-R, Soltanloo H, Ranjbar M (2013) Effects of exogenous methyl jasmonate and 2-isopentenyladenine on artemisinin production and gene expression in Artemisia annua. Turk J Bot 37:499-505

Memelink J, Verpoorte R, Kijne JN (2001) ORCAnization of jasmonate-responsive gene expression in alkaloid metabolism. Trends Plant Sci 6:212-219

Mercke P, Kappers IF, Francel WAV, Oscar V, Marcel D, Harro JB (2004) Combined transcript and metabolic analysis reveals genes involved in cucumber plants. Plant Physiol 135:2012-2024

Merret R, Cirioni JR, Bach TJ, Hemmerlin A (2007) A serine involved in actin-dependent sub-cellular localization of stress induced tobacco BY-2-hydroxymethylglutaryl-CoA-reudctase isoforms. FEBS Lett 581:5295-5299

Miller B, Madilao LL, Ralph S, Bohlmann J (2005) Insect induced conifer defense. White pine weevil and methyl jasmonate induce traumatic resinosis, de novo formed volatile emissions and accumulation of terpenoid synthase and putative octadecanoid pathway transcripts in Sitka spruce. Plant Physiol 137:369-382

Miller JA, Thompson PA, Hakin IA, SherryChow HH, Thomson CA (2011) D-Limonene: a bioactive food component from Citrus and 
evidence for a potential role in breast cancer prevention and treatment. Oncol Rev 5:31-42

Mithofer A, Wanner G, Boland W (2005) Effect of feeding Spodoptera littoralis on lima bean leaves: II. Continuous mechanical wounding resembling insect feeding in sufficient to elicit herbivory-related volatile emissions. Plant Physiol 137:1160-1168

Moses T, Pollier J, Thevelein JM, Goosens A (2013) Bioengineering of plant (tri)terpenoids: from metabolic engineering of plants to synthetic biology in vivo and in vitro. New Phytol 199:1-17

Muffler K, Leipold D, Scheller MC, Haas C, Steingroewer J, Bley T, Neuhans E, Mirata MA, Schrader J, Ulber R (2011) Biotransformation of triterpenes. Process Biochem 46:1-15

Nagegowda DA (2010) Plant volatile terpenoid metabolism: biosynthetic genes, transcriptional regulation and sub-cellular compartmentation. FEBS Lett 584:2965-2973

Nagegowda DA, Bach TJ, Chye ML (2004) Brassica juncea HMGCoA synthase 1: expression and characterization of recombinant wild type and mutant enzymes. Biochem J 383:517-527

Okada K, Saito T, Nakagawa T, Kawamukai M, Kamiya Y (2000) Five geranyl geranyl diphosphate synthase expressed in different organs are localized into the sub-cellular compartments in Arabidopsis. Plant Physiol 122:1045-1056

Papon N, Bremer J, Vansiri A, Andreu F, Rideau M, Creche J (2005) Cytokinin and ethylene control indole alkaloid production at the level of the MEP/terpenoid pathways in Catharanthus roseus suspension cells. Planta Med 71:572-574

Pauwels L, Goosens A (2011) The JA2 proteins: a crucial interface in the jasmonate signaling cascade. Plant Cell 23:3089-3100

Pauwels L, Inze D, Goosens A (2009) Jasmonate inducible gene: what does it mean? Trends Plant Sci 14:87-91

Pegel KH (1997) The importance of sitosterol and sitosterolin in human and animal nutrition. S Afr J Sci 93:263-268

Peters RJ (2006) Uncovering the complex metabolic network underlying diterpenoid phytoalexin biosynthesis in rice and other cereal crops. Phytochemistry 67:2307-2317

Phillips DR, Rasberry JM, Bartel B, Matsuda SPT (2003) Biosynthetic diversity in plant triterpene cyclization. Curr Opin Plant Biol 9:305-314

Phillips MA, Bohlmann J, Gershenzon J (2006) Molecular regulation of induced terpenoid biosynthesis in conifers. Phytochem Rev 5:179-189

Picaud S, Olofsson L, Brodelius M (2005) Expression, purification and characterization of recombinant amorpha-4, 11-diene synthase from Artemisia annua L. Arch Biochem Biophys 436:215-226

Poeckel D, Werz O (2006) Boswellic acids: biological actions and molecular targets. Curr Med Chem 13:3359-3369

Poeckel D, Tausch L, Altmann A, Feisst C, Klinkhardt U, Graff J, Harder S, Werz O (2005) Induction of central signaling pathways and select functional effects in human platelets by $\beta$ boswellic acid. Br J Pharmacol 146:514-524

Poeckel D, Tausch L, George S, Jauch J, Werz O (2006) 3-O-acetyl 11-keto-boswellic acid decreases basal intracellular $\mathrm{Ca}^{2+}$ levels and inhibits agonist-induced $\mathrm{Ca}^{2+}$ mobilization and mitogenactivated protein kinase activation in human monocyte cells. J Pharmacol Exp Ther 316:224-232

Pollier J, Moses T, Goossens A (2011) Combinatorial biosynthesis in plants: a (p) review on its potential and future exploitation. Nat Prod Rep 28:1897-1916

Prins CL, Vieira IJC, Frietas SP (2010) Growth regulators and essential oil production. Braz J Plant Physiol 22:91-102

Prisic S, Xu MM, Wilderman PR, Peters RJ (2004) Rice contains two disparate ent-copalyl diphosphate synthases with distinct metabolic functions. Plant Physiol 136:4228-4236
Qi X, Bakht S, Leggett M, Maxwell C, Melton R, Osbourn A (2004) A gene cluster for secondary metabolism in oat: implications for the evolution of metabolic diversity in plants. Proc Natl Acad Sci USA 101:8233-8238

Qi X, Bakht S, Qin B, Leggett M, Hemmings A, Melton F, Eagles J, Wreck-Reinhardt D, Schaller H, Lesot A, Melton R, Osbourn A (2006) A different function for a member of an ancient and highly conserved cytochrome P450 family: from essential sterols to plant defense. Proc Natl Acad Sci USA 103:18848-18853

Rabi T, Bishayee A (2009a) D-Limonene sensitizes docetaxel-induced cytotoxicity in human prostate cancer cells: generation of reactive oxygen species and induction of apoptosis. J Carcinog $8: 9$

Rabi T, Bishayee A (2009b) Terpenoids and breast cancer chemoprevention. Breast Cancer Res Treat 115:223-239

Rall B, Ammon HP, Safayhi H (1996) Boswellic acids and protease activity. Phytomedicine 3:75-76

Reumann S, Babujee L, Ma C, Weinkoop S, Siemsen T, Antoni Celli GE, Rasche N, Luder F, Weckwerhth W, Jahn O (2007) Proteome analysis of Arabidopsis leaf peroxisomes reveals novel targeting plastids, metabolic pathways and defense mechanisms. Plant Cell 19:3170-3193

Richardson AQ, Palmer JD (2007) Horizontal gene transfer in plants. J Exp Bot 58:1-9

Richelle M, Enslen M, Hager C, Groux M, Tavazzi I, Godin JP, Berger A, Métairon S, Quaile S, Piquet-Welsch C, Sagalowicz L, Green H, Fay LB (2004) Both free and esterified reduce cholesterol absorption and bioavailability of $\beta$-carotene and $\alpha$ tocopherol in normocholesterolemic humans. Am J Clin Nutr 80:171-177

Rieber M, Strasberg Rieber M (1998) Inhibition of p53 without increase in p21WAF1 in betulinic acid-mediated cell death is preferential for human metastatic melanoma. DNA Cell Biol 17:399-406

Rodrìguez-Concepción M (2006) Early steps in isoprenoid biosynthesis: multilevel regulation of the supply of common precursors in plant cells. Phytochem Rev 5:1-15

Rodriguez-Saona C, Crafts-Brandner SJ, Canas LA (2003) Volatile emissions triggered by multiple herbivore damage: beet armyworm and whitefly feeding on cotton plants. J Chem Ecol 29:2539-2550

Rodwell VW, Beach MJ, Bischoff KM, Bochar DA, Darnay BG, Friesen JA, Gill JF, Hedl M, Jordan-Starck T, Kennelly PJ, Kim DY, Wang Y (2000) 3-hydroxy-3-methylglutaryl CoA reductase. Methods Enzymol 324:259-280

Rohdich F, Wungsintaweekul J, Eisenreich W, Richter G, Schuhr CA Hecht S, Zenk MH, Bacher A (2000) Biosynthesis of terpenoids: 4-diphosphocytidyl-2C-methyl-D-erythritol synthase of Arabidopsis thaliana. Proc Natl Acad Sci USA 97:6451-6456

Safayhi H, Rall B, Sailor AR, Ammon HP (1997) Inhibition by boswellic acids of human leucocyte elastase. J Pharmacol Exp Ther 281:460-463

Saldanha SN, Tollefsbol TO (2012) The role of neutraceuticals in chemoprevention and chemotherapy and their clinical outcomes. J Oncol 2012(Article ID 192464):1-23

Salland C, Rontein D, Onillon S, Jabesh F, Duffe P, Giacalone C, Thoraval S, Escoffier C, Herbette G, Leonhardt N, Causse M, Tissier A (2009) A novel pathway for sesquiterpene biosynthesis from farnesyl pyrophosphate in the wild tomato (Solanum habrochaites). Plant Cell 21:301-317

Sapir-Mir M, Mett A, Belausov E, Tal-Meshulam S, Frydman A, Gidoni D, Eyal Y (2008) Peroxisomal localization of Arabidopsis isopentenyl diphosphate isomerases suggests that part of the plant isoprenoid mevalonic acid pathway is compartmentalized to peroxisomes. Plant Physiol 148:1219-1228 
Sawai S, Saito K (2011) Triterpenoid biosynthesis and engineering in plants. Front Plant Sci 2:1-25

Sawai S, Shondo T, Sato S, Kaneko T, Tabata S, Ayabe SI, Aoki T (2006) Functional and structural analysis of genes encoding oxidosqualene cyclases of Lotus japonicus. Plant Sci 170:247-257

Schilmiller AL, Schauvinhold I, Larson M, Xu R, Charbonneau AL, Schmidt A, Wilkerson C, Last RL, Pichersky E (2009) Monoterpenes in glandular trichomes in tomato are synthesized from a neryl diphosphate precursor rather than geranyl diphosphate. Proc Natl Acad Sci USA 106:10865-10870

Schnee C, Köllner TG, Held M, Turting TCJ, Gershenzon J, Degenhardt J (2006) The products of a single maize sesquiterpene synthase form a volatile defense signal that attracts natural enemies of maize herbivores. Proc Natl Acad Sci USA 103:1129-1134

Segura MJR, Meyer MM, Matsuda SPT (2000) Arabidopsis thaliana LUP1 converts oxidosqualene to multiple triterpene alcohols and a triterpene diol. Org Lett 2:2257-2259

Seki H, Ohyama K, Sawai S, Mizutani M, Ohnishi T, Sudo H, Akashi T, Aoki T, Saito K, Muranaka T (2008) Licorice $\beta$-amyrin 11-oxidase, a cytochrome $\mathrm{P} 450$ with key role in the biosynthesis of the triterpene sweetener glycyrrhizin. Proc Natl Acad Sci USA 105:14204-14209

Shah BA, Qazi GN, Taneja SC (2009) Boswellic acid: a group of medicinally important compounds. Nat Prod Rep 26:72-89

Shanmugum MK, Ong TH, Kumar AP, Lun CP, Ho PC et al (2012) Ursolic acid inhibits the initiation, progression of prostate cancer and prolongs the survival of TRAMP mice by modulating proinflammatory pathways. PLoS One 7:e32476

Shao Y, Ho CT, Chin CK, Badmaev V, Ma W, Huang M-T (1998) Inhibitory activity of boswellic acid from Boswellia serrata against human leukemia HL-60 cells in culture. Planta Med 64:328-331

Sheron-Asa L, Shalit M, Frydman A, Bar E, Holland D, Or E, Lavi U, Lewinsohn E, Eyal Y (2003) Citrus fruit flavor and aroma biosynthesis: isolation, functional characterization and developmental regulation of Cstps1, a key gene in the production of the sesquiterpene aroma compound valencene. Plant J 36:664-674

Shibuya M (2004) Cucurbitadienol synthase, the first committed enzyme for cucurbitacin biosynthesis, is a distinct enzyme from cycloartenol synthase for phytosterol biosynthesis. Tetrahedron 60:6995-7003

Shibuya M, Zhang H, Endo A, Shishikura K, Kushiro T, Ebizuka Y (1999) Two branches of the lupeol synthase gene in the molecular evolution of plant oxidosqualene cyclases. Eur $\mathbf{J}$ Biochem 266:302-307

Shibuya M, Xiang T, Katsube Y, Otsuka M, Zhang H, Ebizuka Y (2007) Origin of structural diversity in natural triterpenes: direct synthesis of seco-triterpene skeletons by oxidosqualene cyclase. J Am Chem Soc 129:1450-1455

Shibuya M, Katsube Y, Otsuka M, Zhang H, Tansakul P, Xiang T, Ebizuka Y (2009) Identification of a product specific $\beta$-amyrin synthase from Arabidopsis thaliana. Plant Physiol Biochem 47:26-30

Shimada T, Endo T, Fuji H, Hara M, Veda T, Kita M, Omura M (2004) Molecular cloning and functional characterization of four monoterpene synthase genes from Citrus unshiu Marc. Plant Sci 166:49-58

Siamaru H, Orihara Y, Tansakul P, Kang YH, Shibuya M, Ebizuka Y (2007) Production of triterpene acids by cell suspension cultures of Olea europaea. Chem Pharm Bull 55:784-788

Silveira e Sá RC, Andrade LN, de Sousa DP (2013) A review on antiinflammatory activity of monoterpenes. Molecules 18:1227-1254

Simkin AJ, Guirmand G, Papon N, Courdavault V, Thabet I, Ginis D, Bouzid S, Giglioli-Guivarch N, Clastre M (2011) Peroxisomal localization of the final steps of the mevalonic acid pathway in plants. Planta 234:903-914

Sitthithaworn W, Kojima N, Viroonchatapan E, Suh DY, Iwanami N, Hayashi T, Noji M, Saito K, Niwa Y, Sankawa U (2001) Geranyl diphosphate synthase from Scoparia dulcis and Croton sublyratus. Plastid localization and conversion to a farnesyl diphosphate synthase by mutagenesis. Chem Pharm Bull 49:197-202

Sparge SG, Light ME, van Staden J (2004) Biological activities and distribution of plant saponins. J Ethnopharmacol 94:219-243

Sprenger GA, Schörken U, Wiegest T, Grolle S, Graff AA, Taylor SV, Begley TP, Bringer-Meyer S, Sahm H (1997) Identification of a thiamine dependent synthase in Escherichia coli required for the 1-deoxy-D-xylulose 5-phosphate precursor to isoprenoids, thiamine and pyridoxol. Proc Natl Acad Sci USA 94:1285712862

Steinbacher S, Kaisar J, Eisenreich W, Huber R, Bacher A, Rohdich F (2003) Structural basis of fosmidomycin action revealed by the complex with 2-C-methyl-D-erythritol 4-phosphate synthase (IspC). Implication for the catalytic mechanisms and antimalarial drug development. J Biol Chem 278:18401-18407

Sultana N, Ata A (2008) Oleanolic acid and related derivatives as medicinally important compounds. J Enzyme Inhib Med Chem 23:739-756

Sun J (2007) D-Limonene: safety and clinical applications. Altern Med Rev 12:259-264

Sun TP, Kamiya Y (1994) The Arabidopsis GA1 locus encodes the cyclase ent-kaurene synthase A of gibberellin biosynthesis. Plant Cell 6:1509-1518

Sung CK, Shibuya M, Sankawa U, Ebizuka Y (1995) Molecular cloning of cDNA encoding human lanosterol synthase. Biol Pharm Bull 18:1459-1461

Surie C, Bouvier F, Backhaus RA, Begu D, Bonneu M, Camara B (2000) Cellular localization of isoprenoid biosynthetic enzymes in Marchantia polymorpha. Uncovering a new role of oil bodies. Plant Physiol 124:971-978

Suzuki H, Reddy MS, Naoumkina M, Aziz N, May GD, Huhman DR, Sumner LW, Blount JW, Mendes P, Dixon RA (2005) Methyl jasmonate and yeast elicitor induce differential transcriptional and metabolic re-programming in cell suspension cultures of the model legume Medicago truncatula. Planta 220:696-707

Suzuki M, Xiang T, Ohyama K, Seki H, Saito K, Muranaka T, Hayashi H, Katsube Y, Kushiro T, Shibuya M (2006) Lanosterol synthase in dicotyledonous plants. Plant Cell Physiol 47:565-571

Takahashi S, Kuzuyama T, Watanabe H, Seto H (1998) A 1-deoxy-Dxylulose 5-phosphate reductoisomerase catalyzing the formation of 2-C-methyl-D-erythritol 4-phosphate in an alternative nonmevalonate pathway for terpenoid biosynthesis. Proc Natl Acad Sci USA 95:9879-9884

Takashi M, Fujita F, Uchida K, Yamamoto S, Sawada M, Hatai C, Shimizu M, Tominaga M (2012) 1,8-cineole, a TRPM8 agonist, is a novel natural antagonist of human TRPA1. Mol Pain 8:86

Tamongani S, Mitani M (1993) Oryzalexin S structure: a new stemarane-type rice plant phytoalexin and its biosynthesis. Tetrahedron 49:2025-2032

Tansakul P, Shibuya M, Kushiro T, Ebizuka Y (2006) Dammarenediol-II synthase, the first dedicated enzyme for ginsenoside biosynthesis in Panax ginseng. FEBS Lett 580:5143-5149

Thabet I, Guirimand G, Courdavault V, Papon N, Godet S, Dutillent C, Bouzid S, Giglioli-Guivarch N, Clastre M, Simkin AJ (2011) The sub-cellular localization of periwinkle farnesyl diphosphate synthase provides insight into the role of peroxisomes in isoprenoid biosynthesis. J Plant Physiol 168:2110-2116

Thabet I, Guirimand G, Guihur A, Lanoue A, Courdvault V, Papon N, Bouzid S, Giglioli-Guivarich N, Simkin AJ, Clastre M (2012) Characterization and sub-cellular localization of geranyl

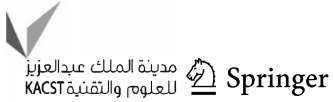


diphosphate synthase from Catharanthus roseus. Mol Biol Rep 39:32-3245

Tholl D (2006) Terpene synthases and the regulation, diversity and biological roles of terpene metabolism. Curr Opin Plant Biol 9:297-304

Tholl D, Lee S (2011) Terpene specialised metabolism in Arabidopsis thaliana. Arabidopsis Book 9:e143

Tholl D, Chen F, Petri J, Gershenzon J, Pichersky E (2005) Two sesquiterpene synthases are responsible for the complex mixture of sesquiterpenes emitted from Arabidopsis flowers. Plant J 42:757-771

Thoppil RJ, Bishayee A (2011) Terpenoids as potential chemopreventive and therapeutic agents in liver cancer. World J Hepatol 3:228-249

Trapp SC, Croteau RB (2001) Genomic characterization of plant terpene synthases and molecular evolutionary implications. Genetics 158:811-832

Traw MB, Bergelson J (2003) Interactive effects of jasmonic acid, salicylic acid and gibberellin on induction of trichomes in Arabidopsis. Plant Physiol 133:879-886

Tsay YH, Robinson GW (1991) Cloning and characterization of ERG8, an essential gene of Saccharomyces cerevisiae that encodes phosphomevalonate kinase. Mol Cell Biol 11:620-631

Turner G, Gershenzon J, Neilson EE, Froehlich JE, Croteau R (1999) Limonene synthase, the enzyme responsible for monoterpene biosynthesis in peppermint, localized to leucoplasts of oil gland secretory cells. Plant Physiol 120:879-886

Unsicker SB, Kunret G, Gershenzon J (2009) Protective perfumes: the role of vegetative volatiles in plant defense against herbivores. Curr Opin Plant Biol 12:479-485

van der Fits L, Memelink J (2000) ORCA3, a jasmonate-responsive transcriptional regulator of plant primary and secondary metabolism. Science 289:295-297

Van Poecke RMP, Posthumus MA, Dicke M (2001) Herbivoreinduced volatile production by Arabidopsis thaliana leads to attraction of the parasitoid Cotesia rubecula: chemical behavioral, and gene-expression analysis. J Chem Ecol 27:1911-1928

Van Schie CCN, Haring MA, Schuurink RC (2007) Tomato linalool synthase is induced in trichomes by jasmonic acid. Plant Mol Biol 64:251-263

Vickers CE, Gershenzon J, Lerdan MT, Loreto F (2009) A unified mechanism of action for volatile isoprenoids in plant abiotic stress. Nat Chem Biol 5:283-291

Vigushin DM, Poon GK, Boddy A, English J, Harbert GW, Pagonis C, Jarman M, Coombs RC (1998) Phase I and pharmacokinetic study of D-limonene in patients with advanced cancer. Cancer Chemother Pharmacol 42:111-117

Vogel BS, Wildung M, Vogel G, Croteau R (1996) Abietadiene synthase from grand fir (Abies grandis). J Biol Chem 271:23262-23268

Vogg G, Fischer S, Leide J, Emmanuel E, Jetter R, Levy AA, Riedrer M (2004) Tomato fruit cuticular waxes and their effects on transpirational barrier properties: functional characterization of mutant deficient in a very long chain fatty acid $\beta$-ketoacyl-CoAsynthase. J Exp Bot 55:1401-1410

Vranova E, Coman D, Gruissem W (2012) Structure and dynamics of the isoprenoid pathway network. Mol Plant 5:318-333

Wagner KH, Elmadfa I (2003) Biological relevance of terpenoids. Overview of focusing on mono-, di- and tetraterpenes. Ann Nutr Metab 47:95-106

Wang YD, Yuan YJ, Lu M, Wu JC, Jiang JL (2003) Inhibitor studies of isopentenyl pyrophosphate biosynthesis in suspension cultures of the new Taxus chinensis var. mairei. Biotechnol Appl Biochem 37:39-43

Wang Z, Yeast T, Han H, Jetter R (2010) Cloning and characterization of oxidosqualene cyclases from Kalanchoe daigremontiana: enzymes catalyzing up to ten rearrangement steps yielding friedelin and other triterpenoids. J Biol Chem 285:29703-29712

Wang Z, Guhling O, Yao R, Li F, Yeast TH, Rose JKC, Jetter R (2011) Two oxidosqualene cyclases responsible for biosynthesis of tomato fruit cuticular triterpenoids. Plant Physiol 155:540-552

Wen $\mathrm{CH}$, Tseng YH, Chu FH (2012) Identification and functional characterization of a sesquiterpene synthase gene from Eleutherococcus trifoliatus. Holzforschung 66:183-189

Wildung MR, Croteau R (1996) A cDNA clone for taxadiene synthase, the diterpene cyclase that catalyzes the committed step of taxol biosynthesis. J Biol Chem 271:9201-9204

Williams DC, McGarvey DJ, Katahira EJ, Croteau R (1998) Truncation of limonene synthase preprotein provides a fully active 'pseudomature' from this monoterpene cyclase and reveals the amino-terminal arginine pair. Biochemistry 37:12213-12220

Wilt TJ, Ma Donald R, Ishani A (1999) $\beta$-Sitosterol for the treatment of benign prostate hyperplasia: a systematic review. BJU Intl 83:976-983

Withers ST, Keasling JD (2007) Biosynthesis and engineering of isoprenoid small molecules. Appl Microbiol Biotechnol 73:980-990

Wong RJ, McCormack DK, Russell DW (1982) Plastid 3-hydroxy-3methylglutaryl $\mathrm{CoA}$ reductase has distinctive kinetic and regulatory features: properties of the enzyme and positive phytochrome control of activity in pea seedlings. Arch Biochem Biophys 216:631-638

Worth H, Schacher C, Dethlefsen U (2009) Concomitant therapy with cineole (eucalyptole) reduces exacerbations in COPD: a placebocontrolled double-blind trial. Respir Res 10:69

Wu SQ, Schalk M, Clark A, Miles RB, Coates R, Chappel J (2006) Re-direction of cytosolic or plastidic isoprenoid precursors elevates terpene production in plants. Nat Biotechnol 24:1441-1447

Xi Z, Bradley RK, Wurdack KJ, Wong KM, Sugumaran M, Bomblies K, Rest JS, Davis CC (2012) Horizontal transfer of expressed genes in parasitic flowering plants. BMC Genom 13:227

Xiang T, Shibuya M, Katsube Y, Tsutsumi T, Otsuka M, Zhang H, Masuda K, Ebizuka Y (2006) A new triterpene synthase from Arabidopsis thaliana produces a tricyclic triterpene with two hydroxyl groups. Org Lett 13:2835-2838

Xue Z, Duan L, Liu D, Guo J, Ge S, Dicks J, Omaille P, Osbourn A, Qi X (2012) Divergent evolution of oxidosqualene cyclases in plants. New Phytol 193:1022-1038

Yamaguchi S, Saito T, Abe H, Yamane H, Murofushi N, Kamiya Y (1996) Molecular cloning and characterization of a cDNA encoding the gibbrellin biosynthesis enzyme ent-kaurene synthase B from pumpkin (Cucurbita maxima L.). Plant J 10:203-213

Yamaguchi S, Sun TP, Kawaide H, Kamiya Y (1998) The GA2 locus of Arabidopsis thaliana encodes ent-kaurene synthase of gibberellin biosynthesis. Plant Physiol 117:1271-1278

Yoon WJ, Lee NH, Hyun CG (2010) Limonene suppresses lipopolysaccharide-induced production of nitric oxide, prostaglandin E2 and pro-inflammatory cytokines in RAW 264-7 macrophages. J Oleo Sci 59:415-421

Yu J, Wang J, Lin W, Li SG, Li H, Zhou J, Ni PX, Dong W, Hu SN, Zeng CQ et al (2005) The genomes of Oryza sativa: a history of duplications. PLoS Biol 3:e38

Zapta F, Fine PA (2013) Diversification of the monoterpene synthase gene family (Tpsb) in Protium, a highly diverse genus of tropical tree. Mol Phylogenet Evol 68:432-442

Zhang H, Shibuya M, Yokota S, Ebizuka Y (2003) Oxidosqualene cyclases from cell suspension cultures of Betula platyphylla var. japonica: molecular evolution of oxidosqualene cyclases in higher plants. Biol Pharm Bull 26:642-650 
Zhang JP, Kang J, Huang SG, Chen P, Yao WZ, Yang L, Bai CX, Wang CZ, Wang C, Chen BY, Shi Y, Liu CT, Chen P, Li Q, Wang ZS, Huang YJ, Luo ZY, Chen FP, Yuan JZ, Yuan BT, Qian HP, Zhi RC, Zhong NS (2008) Effect of carbocisteine on acute exacerbation of chronic obstructive pulmonary disease: a randomized placebo-controlled study. Lancet 371:2013-2018
Zhao J, Zheng SH, Fujita K, Sakai K (2004) Jasmonate and ethylene signalling pathway leading to $\beta$-thujaplicin biosynthesis in Cupressus lusitanica cell cultures. J Exp Bot 55:1003-1012

Zulak KG, Bohlmann J (2010) Terpenoid biosynthesis and specialized vascular cells of conifer defense. J Intgr Plant Biol 52:86-97 